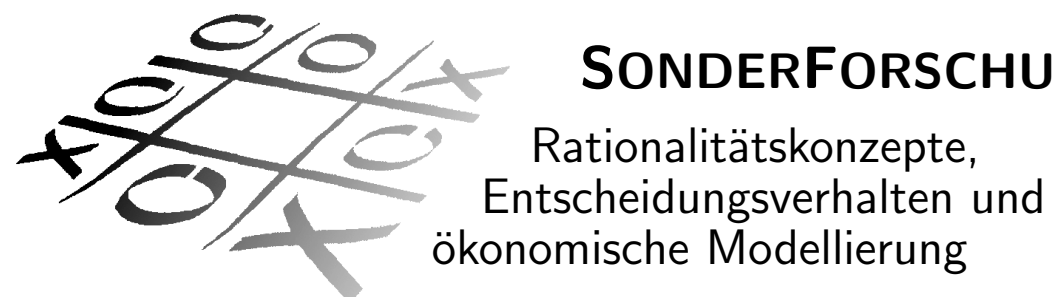

No. $08-42$

From Malthus to Modern Growth: Child Labor, Schooling and Human Capital

Edgar Vogel*

May 2009

I thank Andreas Irmen, Wolfgang Kuhle, Alexander Ludwig, Steffen Reinhold and participants of the CDSE and MEA Seminar for helpful comments. Financial support by the State of Baden-Württemberg, the German Insurers Association (GDV) and the German Science Foundation (DFG, SFB $504)$ is gratefully acknowledged. Please send comments and questions to Vogel.Edgar@utanet.at.

*MEA, University of Mannheim, email: vogel.edgar@utanet.at

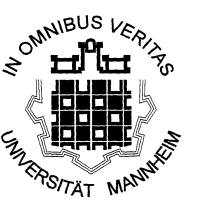

Universität Mannheim

L 13,15

68131 Mannheim 


\title{
From Malthus to Modern Growth: Child Labor, Schooling and Human Capital *
}

\author{
Edgar Vogel \\ MEA, University of Mannheim
}

This version: February 16, 2009

\begin{abstract}
This paper develops a dynamic general equilibrium model of fertility, human capital accumulation, child labor and uncertain child survival focusing on the qualitative and quantitative effect of declining mortality on household decisions and economic development. Due to uncertainty about child survival, parents have a precautionary demand for children. Rising survival probability leads to falling fertility, eventually to investment into schooling and the demise of child labor. Child labor can be an obstacle to development since it lowers the incentives of parents to educate children. Furthermore, the paper argues that the decline of precautionary child demand as a consequence of falling mortality is not sufficient to generate a demographic transition. Falling mortality can only explain a relatively small part of the fertility decline. A sizable reduction in fertility can only be achieved by human capital investment and the induced quantity-quality trade off.
\end{abstract}

JEL classification: J11, J13, I12, O11, O40

Keywords: Demographic transition, child mortality, precautionary demand, child labor, human capital, growth

*I thank Andreas Irmen, Wolfgang Kuhle, Alexander Ludwig, Steffen Reinhold and participants of the CDSE and MEA Seminar for helpful comments. Financial support by the State of Baden-Württemberg, the German Insurers Association (GDV) and the German Science Foundation (DFG) is gratefully acknowledged. Please send comments and questions to Vogel.Edgar@utanet.at. 


\section{Introduction}

Key stylized facts characterizing the evolution of humanity from an era close to subsistence levels to today's high-tech economies are - among other facts - increasing technological progress combined with rising educational attainment and the demise of child labor on the one hand and falling mortality and fertility causing a demographic transition on the other hand. These events have occurred in today's developed countries from the onset of the industrial revolution to present times and are currently under way in developing countries. These stylized facts can therefore be observed both across time and across countries (see section 2). The motivation for this research is to build a model explaining these facts in a general equilibrium setup. Although there is a large body of literature on each of the mentioned items in isolation, work on the combination and interaction of these phenomena is scarce.

To replicate the historically observed sequence of these stylized facts, this paper develops a dynamic general equilibrium model of endogenous fertility, human capital investment decisions, child labor and uncertain child survival. The driving force of the model dynamics is the changing survival rate. Parents maximize utility from own consumption, child leisure and a quantity-quality composite of children. In addition to adult labor supply, parents can choose to send children to work and thus generate additional income. Quality is measured in terms of the child's human capital whereas the quantity refers to the number of surviving children. The macroeconomic piece of the model consists of a production function with human capital and a fixed amount of land as inputs. Technological progress is initially driven by rising population and later additionally by human capital investment.

Employing this framework, the paper makes two contributions to the literature. First, it is the first paper bringing the quantity-quality decision of children on the one hand and child labor on the other hand in an analytically tractable framework with uncertainty, inspired by the seminal contribution of Kalemli-Ozcan (2003), together. Second, it provides quantitative evidence on the contribution of falling mortality, rising schooling and the role of child labor to the demographic transition. Using a calibrated version of the model it is shown that the decrease of precautionary demand for children as a consequence of falling mortality is able to explain a small drop in fertility but it is unlikely to be the main driving force of the demographic transition. The reversal of the relationship between income, mortality and population growth is ultimately triggered by the quantity-quality trade off which forces parents to curb fertility in order to endow children with schooling. We find that child labor is a potential obstacle to development in a sense that the more children can earn on the labor market, the higher is fertility and the lower is schooling. Moreover, the model is able to generate the historically observed sequencing and qualitative behavior of fertility, population growth, child labor and schooling. Initially, sending children to school is not optimal but children work and fertility is declining whereas population growth is rising. Later - with falling mortality - fertility and child labor decrease and schooling becomes optimal. This fuels technological progress which further rises survival rates, decreases fertility and child labor. Eventually, parents choose not to send their children to work but invest only into their education.

Recently, the link between child labor and human capital accumulation has shifted into the focus of growth and development economics. Basu and Van (1998) present a model in which parents are not selfishly exploiting their children but let their children work because additional income close to subsistence levels is the welfare maximizing household solution. They also

discuss the possibility of multiple equilibria. Hazan and Berdugo (2002) develop a model with 
child labor and schooling decision. Their central result is that technological progress increases the wage differential between children and adults leading to reduced child labor and more education. Baland and Robinson (2000) investigate the role of capital market imperfections and the role of bequests for child labor. They find that child labor is inefficient if parents can use children's income as a substitute for negative bequests or are credit constrained. Dessy (2000) argues that child labor may be the obstacle to development. If the economy is sufficiently close to a critical value of per capita human capital, the presence of child labor may pull the economy into a poverty trap which can be avoided by introducing compulsory schooling. Strulik (2004a) presents a model with child mortality and child labor and Strulik (2004b) additionally includes child health affecting child survival. Depending on the child survival rate, the economy can be stuck in a high-fertility and low growth regime with child labor or in a low fertility and perpetual growth environment. The demographic transition is generated by a quantity-quality mechanism pioneered by Becker and Lewis (1973) and Becker (1960).

The choice of human capital investment under uncertain survival has been considered in Kalemli-Ozcan (2003) and in a general equilibrium setup in Kalemli-Ozcan (2002). Parents have a "precautionary" demand for children. As a consequence of this, high mortality rates and thus high uncertainty about the survival of offspring will induce parents to have more children but endow them with little education. Lowering the risk will decrease precautionary demand and accelerate investment into schooling. In the same spirit, Tamura (2006) presents numerical evidence showing that this family of models can be used to generate realistic results for important macro- and microeconomic variables (life expectancy, fertility, population, mortality, etc.). Using a perpetual youth model Kalemli-Ozcan et al. (2000) show that a reduction in the mortality rate at any age significantly increases investment into human capital. Empirical studies confirm these findings. In an econometric analysis using Swedish fertility data, Eckstein et al. (1999) find that both increases in real wages and reductions in infant and child mortality significantly contributed to the fertility decline. Most important was, however, the decline in mortality. Similar findings are confirmed for India by Ram and Schultz (1979) who argue that falling mortality was an important incentive to invest into education.

There is an enormous amount of literature offering a wide range of alternative explanations for the demographic transition and the rise of human capital investment. The seminal paper by Galor and Weil (2000) generates the transition from a Malthusian development stage to a growing economy by endogenously raising the rate of technological progress and thereby human capital investment. Hansen and Prescott (2002) examine a model with an agricultural sector with a fixed factor (land) and a modern technology with constant returns. Assuming exogenous technological progress in both sectors, the modern sector will eventually be more productive and pull the economy out of the Malthusian trap. Galor and Weil (1996) derive the fertility decline from a narrowing wage gap between men and women. By increasing the value of female labor, the costs of child rearing increase and thus the transition from a high fertility to a low fertility regime is achieved. In the model of Cervellati and Sunde (2005) the driving force of development is the rising life expectancy. Assuming that education incurs a fixed (time) cost, rising life expectancy makes education more attractive and thus agents will engage into education as their planning horizon expands. Jones (2001) is proposing a mechanism in which the introduction of property rights plays the key role in explaining growth and the demographic transition over long periods. Other explanations for the demographic transition are rooted in evolutionary economics with people having a preference for child quality eventually dominating Galor and Moav (2002) or changes in marriage institutions with an increasing share of women with higher human capital Gould et al. (2008). 
Stylized facts motivating this research are presented in section 2. Section 3 introduces the model environment and outlines the household's maximization problem. Section 4 describes the macroeconomic setup. Section 5 closes the model by establishing the links between household decisions and aggregate behavior on the one hand and the dynamic behavior of the model on the other hand. In the same section we also present the results from a calibration exercise. Section 6 concludes.

\section{Stylized Facts}

This section presents stylized facts motivating this research in some more detail. Note that all facts hold true for the modern world with poor and rich countries (i.e. for the cross section) and in a time series perspective using historical data for today's developed countries.

Figure 1 plots the percentage of working children against GDP per capita. The blue dots are numbers for the years 1960-2001. The red dots are the numbers for the year 2002 revealing that child labor is still a widely spread phenomenon in today's world. In countries like Mali, Bhutan and Burundi almost 50\% of the children aged 10-14 participate in the labor market and are thus an important source of family income. In the 1960s and 1970s, the share of working children was even higher. In Mali, Nepal and Burkina Faso more than half of all children had to work in order to contribute to family income. Using income per capita as a benchmark, these numbers are comparable to historical statistics. According to Lebergott (1964) at the end of the $19^{\text {th }}$ century between 13 and 18 percent of all children aged 10-15 in the US were actively participating in the labor market, working even in industries like mining or manufacturing and a ten year old boy employed in agriculture had the earning capacity of about one quarter of an adult. The second empirical regularity observed in the

Figure 1: GDP per Capita and Child Labor

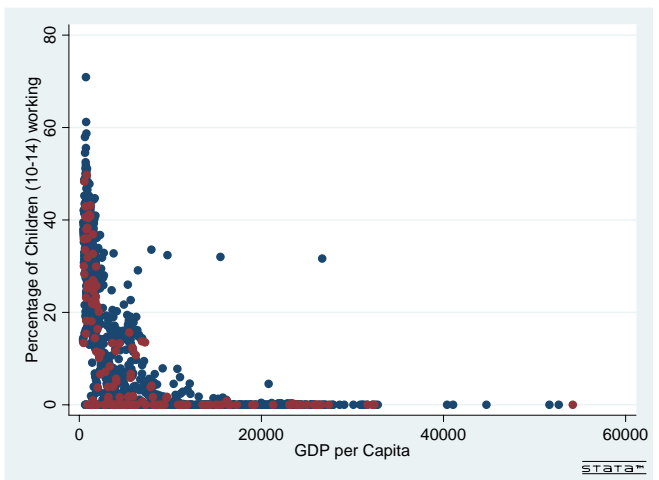

Notes: Blue dots: 1960,1970,1980,1990,1998-2001. Red dots: 2002. Source: The World Bank (2004).

data is the strong negative correlation of child or infant mortality and income per capita. ${ }^{1}$ Figure 2 shows that as income approaches very low (subsistence) levels, child mortality rises dramatically. Income beyond this threshold has a relatively minor influence. As a glance

\footnotetext{
${ }^{1}$ There is a strong positive correlation $(\rho>0.8$, based on data from The World Bank (2004)) between adult and infant mortality suggesting that high child mortality is also a good proxy for health conditions over the entire life span.
} 
Figure 2: GDP per Capita and Child Mortality

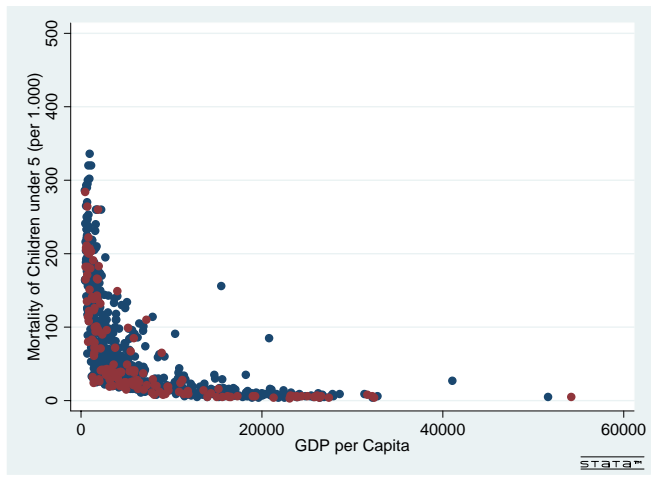

Notes: Blue dots: 1960,1970,1980,1990,1998-2001. Red dots: 2002.

Source: The World Bank (2004).

on the blue and red dots (indicating again 1960-2001 and 2002 separately) reveals, there has been no large gain in child survival probabilities for these low income countries despite the huge gains in medical knowledge worldwide which suggests that income seems to be the most important factor determining child mortality. Historical statistics from Sweden (Wolpin (1997)) and England (Cutler et al. (2006)) confirm this result. Infant mortality was high and the chance to survive age 15 were as low as 60-70\%. Survival probabilities conditional on having survived childhood were much higher. Due to high mortality rates earlier in life, life expectancy at birth around 1850 in England was 40 years, conditional on being 10 years old 55 years and close to 70 years at the age of 45 . Thus, the dramatic increase in life expectancy came first from eliminating the risks early in life. Huge improvements in life expectancy later in life were achieved only in more recent times.

The trade off between quality and quantity is another regularity present in the data and shown in figure 3. There is a clear negative correlation between the enrolment rate at any schooling level and the total number of births per woman. Again, the same conclusion can be obtained from a time series perspective. French enrolment rates of children (aged 5-14) to primary school increased from 30\% in 1830 to almost 90\% in 1900. In England, the fraction of children with primary education was about $20 \%$ in 1860 and reached $80 \%$ in 1900 . At the same time the number of birth per woman declined dramatically (Flora et al. (1983)). The "corollary" of the higher survival rates and rising schooling is that the pattern of population growth has changed too. Initially, rising survival rates increased population growth but for rising income this relationship turned negative. As can be seen in figure 4, population growth for the Less Developed Countries is hump-shaped, peaked at 2.7\% around 1965 and has been declining since then. The same hump-shaped pattern can be verified for today's developed countries with the peak roughly 100 years earlier.

\section{The Model}

Consider an OLG economy where agents live for two periods and survival to the second period is uncertain. In the first period they are children and can work, receive some education 
Figure 3: Fertility and Enrollment Rate

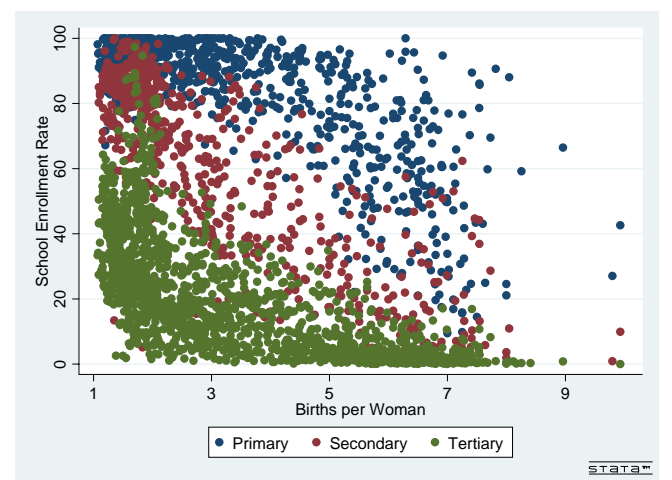

Notes: For primary and secondary enrolment rates are net enrolment rates, for tertiary education gross enrolment rates.

Source: The World Bank (2004).

Figure 4: Population Growth in LDCs and Western Europe
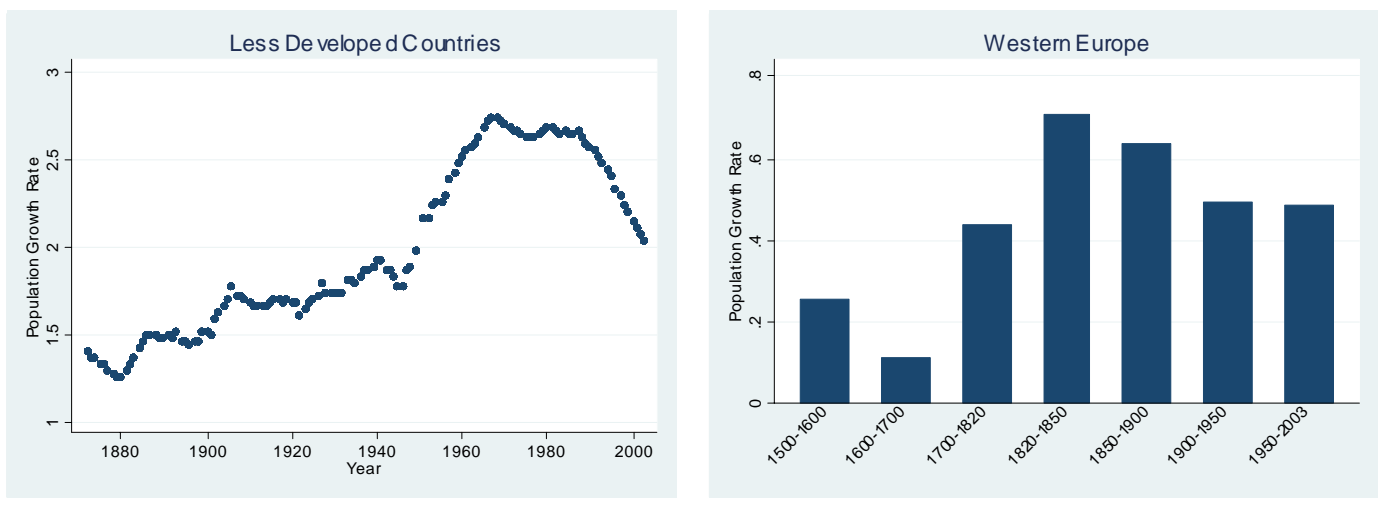

Notes: LDC: Africa, Latin America and Asia (without Japan), 5 year moving average. Western Europe: Austria, Belgium, Denmark, Finland, France, Germany, Greece, Ireland, Italy, Netherlands, Norway, Portugal, Spain, Sweden, Switzerland, UK.

Source: Maddison (2001)

(which enhances their adult human capital) or do both at the same time. Uncertainty concerning their survival is unraveled at the end of the first period. The earnings from their labor supply accrues to the parents. As adults, they consume their total income and make a one-time fertility decision about the desired number of children, children's labor supply and educational attainment. Adults do not leave any bequests. Time is discrete and is extending into the infinite future. The economy produces a single consumption good using two factors of production: human capital and land.

\subsection{Household behavior}

In this setup households choose consumption $c_{t}$, the number of newborns $n_{t}$, child labor supply $\ell_{t}$ and schooling investment $s_{t}$ they give to each child. Preferences are defined over 
adult consumption $c_{t}$, the future earnings of the surviving children $q_{t} n_{t} h_{t+1} w_{t+1}$ where $q_{t}$ is the probability to survive to adulthood, $n_{t}$ is the number of children, $h_{t+1}$ is the human capital of each child and $w_{t+1}$ is the wage per unit of human capital. Parents also derive utility from child leisure $\left(1-\ell_{t}\right)$ where $\ell_{t}$ is child labor supply. For simplicity we assume that $n_{t}$ is continuous, or, we deal with an average individual in the economy. The utility function of generation $t$ can be thus written as

$$
U_{t}=\gamma_{1} \log \left(c_{t}\right)+\gamma_{2}\left\{\mathbb{E}\left[\ln \left(q_{t} n_{t} h_{t+1} w_{t+1}\right)\right]\right\}+\gamma_{3} \ln \left(1-\ell_{t}\right)
$$

where expectations are taken with respect to the child survival rate $q_{t}$. In this model, the survival probability refers to the chances to survive to the age until children start making own economic decisions. Due to this simple setup it is not possible to distinguish between infant, early and late childhood mortality. Assuming that children's survival rate is binomially distributed and using the method of Kalemli-Ozcan (2003), the above expected utility maximization can be approximated ${ }^{2}$ by

$$
U_{t}=\gamma_{1} \ln \left(c_{t}\right)+\gamma_{2}\left[\ln \left(q_{t} n_{t} h_{t+1} w_{t+1}\right)-\frac{1-q_{t}}{2 n_{t} q_{t}}\right]+\gamma_{3} \ln \left(1-\ell_{t}\right)
$$

The difference to a standard maximization problem without uncertain child survival is the remainder term in the parentheses. Low survival probability generates large disutility which can be minimized by having more children. The economic consequence of this additional term is that it generates a "precautionary" demand for offspring. ${ }^{3}$ Note that this additional term vanishes if the survival probability approaches unity. Naturally, with $q_{t}=1$ there is no more risk and we are back in the certainty case.

Human capital is produced according to

$$
h_{t+1}=\left(\underline{\mathrm{s}}+s_{t}\right)^{\xi}
$$

where $\underline{\underline{s}}$ and $\xi$ are parameters and $s_{t}$ is schooling investment into the children's human capital. ${ }^{4}$ Investment in schooling has - from the households' point of view - only private benefits and households do not take possible externalities of schooling into account. Without investment into schooling, the stock of human capital is a constant scaling factor.

Adults supply labor inelastically and use a portion of their remaining time - here standardized to unity - on rearing children and (if optimal) educating them. There are no tuition fees: the cost of education are only parent's opportunity costs. ${ }^{5}$ Each child consumes a fixed share $v \in(0,1)$ of the parents' time which is independent of the number of children. This fixed cost per child is assumed to capture forgone wages, nutrition, clothing or other relevant expenditures. On the other hand, children can be sent to work and earn a fraction $\theta<1$ of

\footnotetext{
${ }^{2}$ This is basically a third order approximation of the log-function evaluated at the mean of the distribution. See appendix B for a derivation of the approximation.

${ }^{3}$ See also Sah (1991) for an application of a similar idea to parental welfare.

${ }^{4}$ There is no interaction between working and school. Some authors (e.g. Strulik (2004a)) assume that if children work, the efficiency of schooling is diminished and the accumulation process of human capital is less efficient. Although there is empirical evidence that labor has a negative effect on school achievement (Psacharopoulos (1997)), we ignore this issue here since it alters only the quantitative but not the qualitative aspects of the model.

${ }^{5}$ The introduction of tuition fees does not affect the qualitative results as long as they are proportional to income. For a model with schooling costs depending on parents' human capital see de la Croix and Doepke (2003).
} 
an adult's wage. The budget constraint is then

$$
c_{t}=w_{t} h_{t}\left[1-\left(v+s_{t}\right) n_{t}\right]+\theta w_{t} h_{t} \ell_{t} n_{t} .
$$

Additional constraints are the (natural) "birth limit" restriction $n_{t} \leq 1 / v^{6}$, non-negative consumption, non-negative schooling investment, and non-negative child labor supply. Additionally, we make the following assumptions:

Assumption 1. $v>\theta$.

Assumption 2. $v \xi-\underline{s}>0$

Assumption 3. $v-\underline{s}-\theta>0$

Assumption 1 is needed to ensure that children are always a monetary cost to parents. Assumption 2 guarantees that parents will invest into schooling in an environment without mortality risk. Finally, assumption 3 guarantees that there is always an interior solution.

\subsection{Solution to the Household's Problem}

Solving the household's decision problem gives the following first order conditions for the schooling decision, child labor supply and the number of offspring

$$
\begin{aligned}
\Delta\left(s_{t}, \lambda\right) & \equiv \frac{\gamma_{2} \xi}{\underline{\mathrm{s}}+s_{t}}-\lambda w_{t} h_{t} n_{t}, \\
& =0 \quad \text { if } \quad s_{t}>0 \\
& <0 \quad \text { if } \quad s_{t}=0 \\
\Delta\left(\ell_{t}, \lambda\right) & \equiv \frac{\gamma_{3}}{1-\ell_{t}}-\lambda w_{t} h_{t} n_{t} \theta, \\
& =0 \quad \text { if } \quad \ell_{t} \in(0,1) \\
& >0 \quad \text { if } \quad \ell_{t}=0 \\
\Delta\left(n_{t}, \lambda\right) & \equiv \lambda w_{t} h_{t}\left(v+s_{t}-\theta \ell_{t}\right)-\gamma_{2}\left[\frac{1}{n_{t}}+\frac{\left(1-q_{t}\right)}{2 n_{t}^{2} q_{t}}\right] \\
& =0 \quad \text { if } \quad n_{t} \in\left(0, \frac{1}{v}\right) \\
& <0 \quad \text { if } \quad n_{t}=\frac{1}{v},
\end{aligned}
$$

where $\lambda$ is the multiplier attached to the budget constraint and $\Delta\left(x_{t}, \lambda\right)$ is the derivative of the Lagrangian with respect to $x_{t}$. Conditions (5a) and (5b) require that the marginal utility of schooling or child labor supply is larger or equal than the marginal utility of (forgone) consumption. The third equation (5c) requires that the marginal utility of children (quantity) is larger or equal to the lost income in terms of consumption.

Because of the various constraints these conditions need not be satisfied always with equality. In fact, some of the binding constraints and the associated corner solutions will be defining

\footnotetext{
${ }^{6}$ An alternative interpretation is that $1 / v$ is a social norm for the maximum number of children.
} 
features of different stages of development. The inequality signs below the FOC's for the interior solutions provide the intuition for the corner solutions. Obviously, schooling and labor supply have always a unique solution (either interior or corner solution). The equation for the optimal number of children is nonlinear in $n_{t}$. Nevertheless, it can be shown that there is either a corner or a unique interior solution with a strictly positive number of children. ${ }^{7}$ The intuition behind these results is that marginal utility is bounded for corner solutions in (5a) and (5b) but unbounded from below for the number of newborns. Thus, parents will avoid zero children at any cost but corner solutions with zero schooling or zero child labor are possible. We will discuss the solution to the model in detail further below.

Since each adult has $n_{t}$ children but only a share $q_{t}$ survives to the next period, the population growth rate is given by

$$
g_{N}=L_{t+1} / L_{t}-1=n_{t} q_{t}-1,
$$

where $L_{t}$ is the size of the adult population at period $t$.

Equations (5b), (5a) and (5c) can be solved analytically to obtain closed form solutions. We do this for schooling and labor supply but show the optimal number of children only as an implicit function of the survival rate. ${ }^{8}$ Assume that the survival rate is low and parents do not invest into human capital but have working children. Then parents only choose child labor supply and the number of children:

$$
\begin{aligned}
& \ell_{t}=\frac{\gamma_{1}}{\gamma_{1}+\gamma_{3}}-\frac{\left(1-n_{t} v\right) \gamma_{3}}{n_{t} \theta\left(\gamma_{1}+\gamma_{3}\right)} \\
& n_{t}\left[\frac{n_{t}(v-\theta) \gamma_{1}+\gamma_{3}}{1-n_{t}(v-\theta)}-\gamma_{2}\right]=\gamma_{2} \frac{1-q_{t}}{2 q_{t}}
\end{aligned}
$$

After some time, the survival rate may have increased sufficiently to induce parents to invest into schooling. The optimal choice of schooling, child labor and number of children is given by:

$$
\begin{aligned}
& s_{t}=\frac{\xi \gamma_{2}}{n_{t}\left(\gamma_{1}+\xi \gamma_{2}+\gamma_{3}\right)}-\frac{(v-\theta) \xi \gamma_{2}+\underline{\mathrm{s}}\left(\gamma_{1}+\gamma_{3}\right)}{\left(\gamma_{1}+\xi \gamma_{2}+\gamma_{3}\right)} \\
& \ell_{t}=\frac{\gamma_{1}+\xi \gamma_{2}}{\left(\gamma_{1}+\xi \gamma_{2}+\gamma_{3}\right)}-\frac{\left(1-n_{t}(v-\underline{\mathrm{s}})\right) \gamma_{3}}{n_{t} \theta\left(\gamma_{1}+\xi \gamma_{2}+\gamma_{3}\right)} \\
& n_{t}\left[\frac{n_{t}(v-\underline{\mathrm{s}}-\theta) \gamma_{1}+\xi \gamma_{2}+\gamma_{3}}{1-n_{t}(v-\underline{\mathrm{s}}-\theta)}-\gamma_{2}\right]=\gamma_{2} \frac{1-q_{t}}{2 q_{t}}
\end{aligned}
$$

If for some survival rate child labor is endogenously abandoned, parents decide about optimal

\footnotetext{
${ }^{7}$ In fact, this is a quadratic equation and in appendix $\mathrm{A}$ it is shown that it has always a positive and a negative root.

${ }^{8}$ Since $n_{t}$ is a quadratic equation it is possible to obtain a closed form solution. However, the result is rather cumbersome and is of no use for the remainder of the paper.
} 
schooling and children according to:

$$
\begin{aligned}
& s_{t}=\frac{\xi \gamma_{2}}{n_{t}\left(\gamma_{1}+\xi \gamma_{2}\right)}-\frac{v \xi \gamma_{2}+\underline{\mathrm{s}} \gamma_{1}}{\left(\gamma_{1}+\xi \gamma_{2}\right)} \\
& n_{t}\left[\frac{n_{t}(v-\underline{\mathrm{s}}) \gamma_{1}+\xi \gamma_{2}}{1-n_{t}(v-\underline{\mathrm{s}})}-\gamma_{2}\right]=\gamma_{2} \frac{1-q_{t}}{2 q_{t}}
\end{aligned}
$$

Assume that $q_{t}$ and preferences are such that neither schooling nor child labor supply are positive at the optimal solution. Then parents face only a fertility-consumption trade off. The number of children is then implicitly defined by

$$
n_{t}\left[\frac{v \gamma_{1} n_{t}}{1-n_{t} v}-\gamma_{2}\right]=\gamma_{2} \frac{1-q_{t}}{2 q_{t}}
$$

In principle there is also one "pathological" solution to the household problem. Assume that $\underline{\mathrm{s}}=0$ and that parents' valuation of child leisure $\gamma_{3}$ is very low. For a low survival rate it is possible that the number of children equals the maximum fertility limit $1 / v$ with child labor and schooling being both positive. Put differently, due to high uncertainty parents wish to have as many children as possible but then children finance parents' consumption and their own schooling by working. We exclude this case by a restriction on the model's parameters.

The solution to the households' maximization problem reveals that the nature of household solution does not change qualitatively during the different stages of development. Schooling decreases with the number of children (quantity-quality trade off) and child labor is higher if the number of children is higher. Which regime prevails thus depends on the parameter constellation. By the choice of the parameters (mainly $\theta$, s and $\gamma_{3}$ ) one can obtain all possible solutions ranging from no child labor and no schooling to an interior solution with simultaneous working and schooling or a realistic solution for low mortality environments without child labor but schooling investment.

The optimal reaction of the household to exogenous changes in the survival rate are summarized in the following propositions.

Proposition 1. If the survival rate is increasing the number of newborns $n_{t}$ is decreasing.

Proof. See appendix A.

Proposition 2. If the survival rate is increasing schooling is increasing (if positive) and child labor is decreasing (if positive).

Proof. See appendix A.

Proposition 3. There exists always a survival rate $\tilde{q}_{l}$ low enough such that optimal schooling is zero if $\partial h_{t+1} / \partial s_{t}<\infty$. If preferences and relative child productivity $\theta$ are such that child labor is optimal for $q_{t}<\tilde{q}_{l}$, then the threshold value $\tilde{q}_{l}$ is an increasing function of $\theta$. 
Proof. From equations (8a) or (9a) we see that schooling is a negative function of the number of children. Thus, there is threshold value $\tilde{n}_{t}$ such that schooling is zero. Using proposition 1 we can conclude that there is a survival rate low enough such that $n_{t} \geq \tilde{n}_{t}$ and thus ensuring $s_{t} \leq 0$. The second part can be proven by using that $\partial \tilde{n}_{t} / \partial \theta>0$. The claim $\partial \tilde{q}_{t} / \partial \theta>0$ follows then from the fact that the cross derivative of the left hand side of $(8 \mathrm{c})$ or $(7 \mathrm{~b})$ with respect to $\left\{n_{t}, \theta\right\} \quad \forall n_{t} \in(0,1 / v]$ is negative and the derivative of the right hand side is decreasing in $q_{t}$. Thus, with rising $\theta$ and consequently rising $n_{t}$ for $s_{t}=0$ to hold, we need a higher survival rate.

Propositions 1 and 2 are the results of the interaction of lower precautionary child demand and a quantity-quality trade off. If child survival risk is falling, the number of children will decrease - even without schooling. This is the consequence of falling uncertainty and thus falling precautionary demand for children. With a decreasing number of children parents move out from the corner solution and will endow each offspring with education. Proposition 3 states that if the chance of children to survive to adulthood is low enough, parents will rather invest into quantity and will not endow their offspring with human capital. Moreover, the higher relative child labor productivity, the more likely is that parents will have many children and schooling will be delayed. The intuition is that if the child survival rate is at very low levels, parents would like to have a very high number of offspring to make sure that at least some of them survive. Since they also have a quantity-quality trade off, they will opt for zero schooling. On the other hand the more children can earn, the less costly they are. Thus, high child productivity increases the opportunity costs of schooling which explains why the number of children at the threshold $\tilde{q}_{t}$ is higher $\left(\partial \tilde{n}_{t} / \partial \theta>0\right)$ and schooling will be delayed $\left(\partial \tilde{q}_{t} / \partial \theta>0\right)$.

The behavior of the population growth rate $g_{N}$ is a nonlinear and non-monotonic function of the survival rate which is summarized below:

Proposition 4. Population growth is hump-shaped and has exactly one local maximum if there is no solution to the household problem with $\ell_{t}>0$ and $s_{t}>0$ simultaneously (i.e. no interior solution). If there exists an interior solution, then the population growth rate has the above property only if the population growth rate with child labor and schooling (i.e. interior solution) satisfies

$$
\left.\frac{\partial g_{N}}{\partial q}\right|_{n_{t}=\tilde{n}_{t}} \geq 0
$$

or if the regime without child labor but schooling satisfies

$$
\left.\frac{\partial g_{N}}{\partial q}\right|_{n_{t}=\tilde{n}_{t}} \leq 0
$$

where $\tilde{n}_{t}=\frac{\gamma_{3}}{\gamma_{3}(v-\underline{s})+\theta\left(\gamma_{1}+\xi \gamma_{2}\right)}$ is the number of children where child labor is endogenously aban- 
doned. If one of the two conditions is violated, then the population growth rate has two local maxima.

Proof. See appendix A.

For low $q_{t}$, rising survival probability dominates the drop in the number of children and population growth increases. Intuitively, for large survival risk small changes in the survival probability will not change the optimal solution for $n_{t}$ much. For vanishing survival risk we have the opposite effect. If the incentive to educate children is strong enough, parents will decrease precautionary demand for children and additionally invest more time into each child. Therefore, population growth will decrease at high levels of $q_{t}$. The possible "complications" are caused by the fact that at $\tilde{n}_{t}$ the slope of $\partial n_{t} / \partial q_{t}$ becomes less steep (the number of children is still falling but at a lower pace). This is counterbalanced by rising survival probabilities which increases the population growth rate. Which effect will dominate in the end depends on the parameters of the model.

Proposition 5. If relative child productivity increases, the number of newborns increases.

Proof. See appendix A.

Proposition 6. If relative child productivity increases child labor increases and schooling decreases.

Proof. See appendix A.

The economic interpretation is quite intuitive. If children become relatively more productive on the labor market, the opportunity cost of child leisure goes up and thus child labor supply should rise. At the same time, the cost of children decreases. This is why the number of offspring rises. Schooling decreases because parents are engaged in a quantity-quality trade off.

\subsection{The Steady State Solution}

Assume that the economy grew out from poverty, the child survival rate approaches unity and child labor is abandoned. Then, we are back in a standard Becker-type model with a quantity-quality decision of the parents where only preferences (and some parameters from the human capital production function) determine the solution. Optimal education and number of children are then

$$
\begin{aligned}
n_{s s} & =\frac{(1-\xi) \gamma_{2}}{(v-\underline{\mathrm{s}})\left(\gamma_{1}+\gamma_{2}\right)} \\
s_{s s} & =\frac{\left(1-n_{s s} v\right) \xi \gamma_{2}}{n_{s s}\left(\gamma_{1}+\xi \gamma_{2}\right)}-\frac{\underline{\mathrm{s}} \gamma_{1}}{\gamma_{1}+\xi \gamma_{2}} \\
& =\frac{v \xi-\underline{\mathrm{s}}}{1-\xi}
\end{aligned}
$$


The results confirm the intuition behind the model. Higher fixed costs of children $v$, higher education productivity $\xi$ increases education, higher fixed costs of education $\underline{\mathbf{s}}$, decrease education. Obviously, the opposite is true for the number of children. ${ }^{9}$

\section{The Macroeconomy}

There is one sector producing a homogenous good used for consumption. The production technology uses human capital and an exogenously given amount of land. Output is then produced according to

$$
Y_{t}=A_{t} H_{t}^{\alpha} T^{1-\alpha}
$$

where $H_{t}$ is human capital, $T$ is the fixed amount of land and $A_{t}$ is the level of TFP which grows over time. The fixed amount of land captures the Malthusian nature of the model. In absence of growth in $H_{t}$ or $A_{t}$, a growing population will obviously drive down income per capita. Aggregate human capital is the sum of inelastic adult labor supply and the endogenously determined labor supply of children. I assume that children's and adults' labor are perfect substitutes. Aggregate human capital is then

$$
H_{t}=h_{t}\left(L_{t}+L_{t} \theta \ell_{t} n_{t}\right)
$$

where $L_{t}$ is the number of adults at time $t$ and $\theta \ell_{t} n_{t}$ is the effective labor supply of children. Substituting into equation (14) and rearranging we have

$$
Y_{t}=A_{t} h_{t}^{\alpha}\left(L_{t} \tilde{L}_{t}\right)^{\alpha} T^{1-\alpha}
$$

where $\tilde{L}_{t} \equiv 1+\theta \ell_{t} n_{t}$. Thus, $L_{t} \tilde{L}_{t}$ is total labor supply in the economy. Following the literature (Galor and Weil (2000), Kögel and Prskawetz (2001)), the return to land is zero and income equal average labor productivity with

$$
y_{t}=Y_{t} /\left(L_{t} \tilde{L}_{t}\right)=A_{t} h_{t}^{\alpha}\left(L_{t} \tilde{L}_{t}\right)^{\alpha-1} T^{1-\alpha}
$$

Here, $y_{t}$ is also the income of a family unit consisting of one adult and the children contributing $n_{t} \theta \ell_{t}$ to total labor supply. ${ }^{10}$ In a developed economy without child labor, family and per capita income are identical $\left(\tilde{L}_{t}=1\right)$. The growth rate of efficiency wages is

$$
g_{t}^{y}=g_{t}^{A}+\alpha g_{t}^{h}-(1-\alpha)\left(g_{t}^{L}+g_{t}^{\tilde{L}}\right)
$$

Note that in steady state without child labor and stationary population the solution collapses to $g^{y}=g^{A}$ as in any growth model. During the transition, growth of human capital, changes

\footnotetext{
${ }^{9}$ Note that with certain survival, mortality does not play a role for the optimal number of children and therefore population growth will monotonically increase with $q_{t}$. In such a setup, the number of children will be constant trough time and only a quantity-quality trade off is able to generate a demographic transition.

${ }^{10}$ Income per capita would be smaller than $y_{t}$ since $\theta$ and $\ell_{t}$ are both smaller than unity.
} 
in child labor supply and population dynamics affect the growth rate of wages. Equivalently, we can express the dynamics of income per family as

$$
y_{t+1}=y_{t}\left(1+g_{t}^{A}\right)\left(\underline{\mathrm{s}}+s_{t}\right)^{\xi \alpha}\left(n_{t} q_{t}\right)^{\alpha-1}\left(\frac{1+\theta n_{t+1} \ell_{t+1}}{1+\theta n_{t} \ell_{t}}\right)^{\alpha-1}
$$

where we have substituted $h_{t+1}$, population growth and $\tilde{L}_{t+1}$ out.

\section{General Equilibrium}

This section puts the household solution and the macroeconomic production side together. To close the model we develop the relationships and feedback effects between income, population, technological progress and survival rates. The last subsection presents the simulation results from a calibration exercise using realistic parameter values and data.

\subsection{Technological progress}

The level of technology $A_{t}$ is evolving according to

$$
A_{t}=A_{t-1}\left(1+g_{t-1}^{A}\right)
$$

where $g_{t-1}^{A}$ is the growth rate of technology. Technological progress is determined by the size of the adult population $L_{t}$ and the schooling investment $s_{t}$ with $^{11}$

$$
g_{t}^{A}=g\left(L_{t}, s_{t}\right) \quad g_{t, L}^{A}>0 \quad g_{t, s}^{A}>0 \quad g_{t}^{A}\left(L_{t}, 0\right)>0 .
$$

Technological progress depends here on the size of the population which introduces a strong scale effect. Although there is no clear empirical evidence for this specification in modern economies (Jones (1995)), the assumption seems to be true for a large part of human history (Kremer (1993), Galor and Weil (2000), Diamond (1998)). ${ }^{12}$ Alternative specifications imposing some exogenous minimum $g_{t}^{A}$ if there is no schooling investment and population is below a threshold level lead to similar results. Note that this specification allows for a transitory effect of a larger population on technological progress in a sense that a growing population leads to an acceleration of $g^{A}$. In the case of a stationary population technological progress can further accelerate if investment into human capital is positive.

\subsection{Survival Law}

We assume that idiosyncratic survival risk washes out and the survival rate evolves deterministically on the aggregate level . The survival rate of children $q_{t} \in(0,1]$ is a function of income

\footnotetext{
${ }^{11}$ One could also assume that $g_{A}$ depends on the level of human capital which is the same as to assume that it depends on education since human capital is a function of education.

${ }^{12}$ On the other hand see Crafts and Mills (2007) for the opposite evidence.
} 
per capita $y_{t-1}$ and is given by

$$
q_{t}=q\left(y_{t-1}\right)
$$

with positive first and negative second derivatives and $\lim _{y_{t} \rightarrow \infty} q_{t} \rightarrow 1$. Income per capita enters the survival law in a Malthusian fashion. Falling income per capita decreases the survival probability of children which decreases population (growth) in the next period. By including $y_{t-1}$ instead of $y_{t}$ excludes contemporaneous feedback effects of the number of children on the survival law. ${ }^{13}$

\subsection{The Dynamical System}

The solution to the household problem is the foundation of the dynamic simulation. Given an initial child survival rate $q_{0}$ we can solve the household problem. Then, given an initial adult population $L_{0}$ and initial technological level $A_{0}$ we can feed in the households' decisions into the macroeconomic framework to calculate wages, population, technological progress and survival rates for the next period. Given these values, the entire system can be simulated. Before presenting the simulation results, we first derive some analytical results describing the dynamic behavior of the system. Using equation (19) and expressing all endogenous variables in terms of $y_{t}$ and $y_{t-1}$ we have

$$
\begin{aligned}
y_{t+1}= & y_{t}\left[1+g_{t}^{A}\left(L_{t}, s_{t}\left(y_{t-1}\right)\right)\right]\left[\underline{\mathrm{s}}+s_{t}\left(y_{t-1}\right)\right]^{\xi \alpha} \times \\
& {\left[n_{t}\left(y_{t-1}\right) q_{t}\left(y_{t-1}\right)\right]^{\alpha-1}\left[\frac{1+\theta n_{t+1}\left(y_{t}\right) \ell_{t+1}\left(y_{t}\right)}{1+\theta n_{t}\left(y_{t-1}\right) \ell_{t}\left(y_{t-1}\right)}\right]^{\alpha-1} } \\
L_{t+1}= & L_{t} n_{t}\left(y_{t-1}\right) q_{t}\left(y_{t-1}\right)
\end{aligned}
$$

where $s_{t}=s_{t}\left(n_{t}\left(q_{t}\left(y_{t-1}\right)\right)\right), n_{t}\left(q_{t}\left(y_{t-1}\right)\right)$ and $\ell_{t}\left(n_{t}\left(q_{t}\left(y_{t-1}\right)\right)\right)$. This is a two dimensional $(L, y)$ second order non-linear difference equation which is analytically not tractable. The "nontractability" comes from the fact that the population growth rate is not a monotone function of $y_{t-1}$. It can be seen that $\partial y_{t+1} / \partial y_{t}>0, \partial g_{t}^{A} / \partial y_{t-1}>0$ and $\partial \ell_{t} / \partial y_{t-1}<0$. This is all increasing next period's income. The fact that $\partial n_{t} / \partial y_{t-1}<0$ but $\partial q_{t} / \partial y_{t-1}>0$ makes a statement about the qualitative behavior of the system impossible. Assume that the population growth rate is rising as a consequence of rising survival rates which lowers income. This is counterbalanced by technological progress, rising human capital and falling child labor which pushes available resources per worker up. Thus, if the three factors contributing to rising productivity outweigh the diluting effect of population growth, income will grow, otherwise fall.

Figure 5 shows three simple possible functional forms for the relationship between today's and tomorrow's income per capita. ${ }^{14}$ As can be seen, the strictly concave function has only one solution allowing only for a low income equilibrium $\left(y_{s}^{1}\right)$. Thus, in absence of shifts in technology, income will always converge back to this stable solution. In the case of a strictly

\footnotetext{
${ }^{13}$ This simplifying assumption is needed because otherwise child labor, income and hence survival rates are jointly determined in general equilibrium. Although this is certainly the more realistic assumption, we abstract from this complication since it does not add any additional insights.

${ }^{14}$ There is a fourth solution which is slightly less interesting. If $y_{t+1}$ is strictly convex in $y_{t-1}$ (and the slope is larger than unity at the origin) income is growing without bound for all initial values of income, population, and technological progress.
} 
Figure 5: Solutions to the Difference Equation, $g^{A}\left(L_{t}\right)$ given

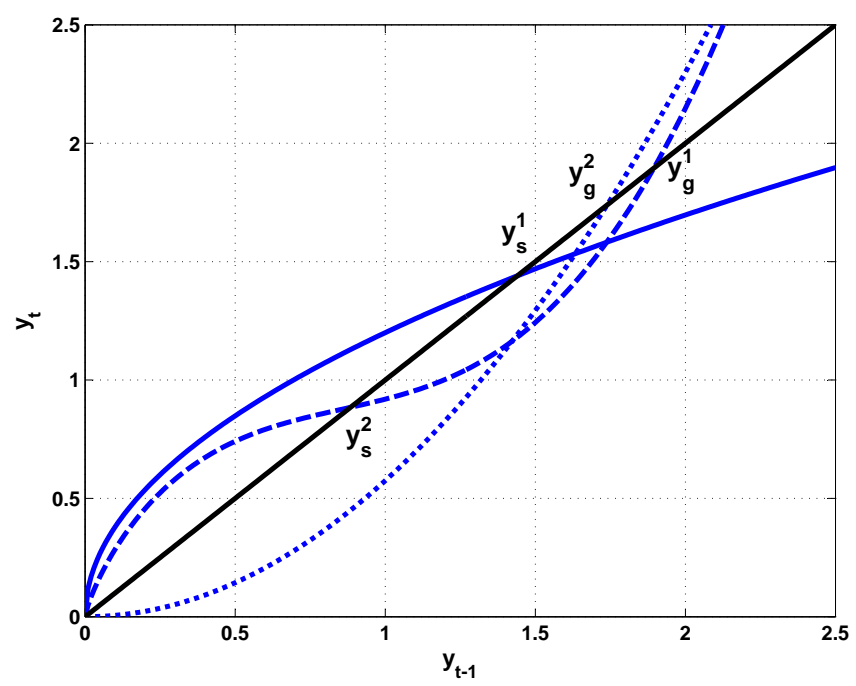

convex function, there are two solutions. If the economy starts out below the threshold $y_{g}^{2}$, income will converge to zero without technological progress. Otherwise, the economy will transit into a regime with endogenous growth. The S-shaped function allows also for two solutions: one stable Malthusian equilibrium $\left(y_{s}^{2}\right)$ and a growing economy $\left(y_{t}>y_{g}^{1}\right)$. Changes in the size of the population and the induced change in the pace of technological progress causes a shift of the curves. As shown in figure 6 a rising population shifts the curves outward.

Note that due to the dependence of $q$ on income and $g^{A}$ on the population size, the economy can be in a situation with temporarily falling income, falling survival rates but accelerating technological progress. In this case there is a "horse-race" between the diluting effect of population size on income on the one hand and positive effect on technological progress on the other hand. In the figure, we simultaneously move along the $y$-schedule to the left and shift the curve outwards due to higher technical progress. The net effect may go in either direction. Such a situation can happen if a country has an initial income per capita (and thus $q_{t}$ ) such that population is growing but the country is not large enough to generate a sufficiently high level of technological progress. Income and survival rates fall reducing $g_{L}$ further and thus slowing down the growth rate of $g_{A}$. If technological progress does not catch up with population growth, the economy falls back to the Malthusian equilibrium. However, even if income temporarily falls back to the Malthusian level, the economy will not necessarily stay there forever.

Proposition 7. If technological progress depends positively on the population size, the economy stays in the Malthusian equilibrium if

$$
-\frac{\partial^{2} g_{A}\left(L_{t}, 0\right) / \partial L_{t}^{2}}{\partial g_{A}\left(L_{t}, 0\right) / \partial L_{t}} L_{t}=1
$$

which is nothing else than requiring the elasticity of the marginal product of population with 
Figure 6: Solutions to the Difference Equation, $g^{A}\left(L_{t}\right)$ varying

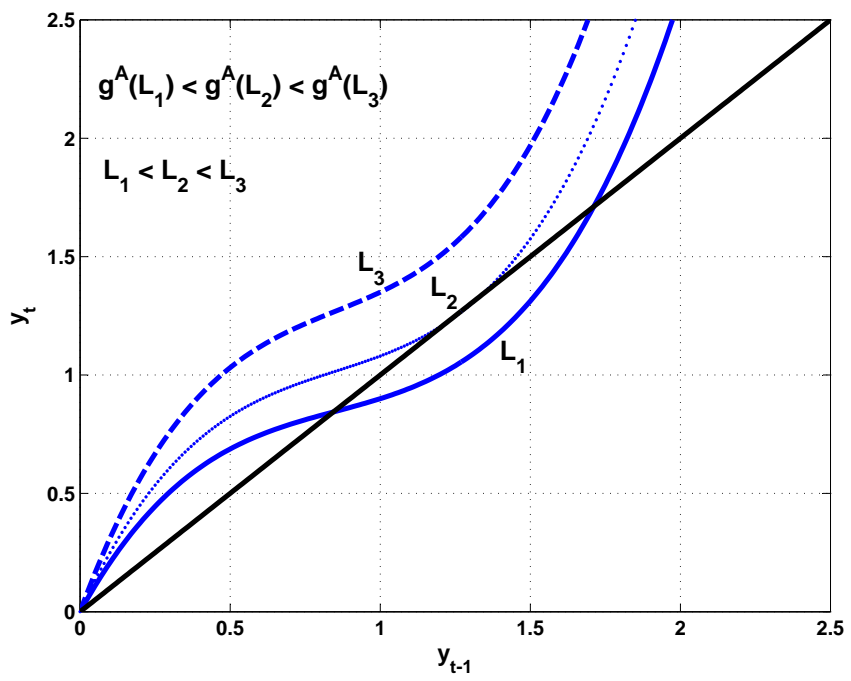

respect to population size to be unity.

Proof. Start with equation (18), assume that schooling is zero (which implies $g_{h}=0$ ) and use the fact that child labor supply is constant $\left(g_{\tilde{L}}=0\right)$. Due to the Malthusian steady state assumption we have $g_{y}=0$ implying $g_{A}\left(L_{t-1}\left(1+g_{L}\right), 0\right)=(1-\alpha) g_{L}$ where we have used $L_{t}=L_{t-1}\left(1+g_{L}\right)$. Taking the derivative with respect to population growth gives

$$
\frac{\partial g_{A}}{\partial L_{t}} L_{t-1}=1-\alpha
$$

With positive population growth this can only hold for all $L_{t}$ if $g_{A}$ is strictly concave in the population size and

$$
\frac{\partial^{2} g_{A}}{\partial L_{t}} L_{t}+\frac{\partial g_{A}}{\partial L_{t}}=0
$$

holds. Rearranging this equation proves the claim.

The previous proposition states that the growth rate of TFP should not accelerate "to fast", or the rate of increase has to decrease fast enough to just counterbalance population growth. ${ }^{15}$ Then, income per capita will stay constant and so will the survival rate. Note that if we impose an exogenous growth rate $\bar{g}^{A}$ for TFP or alternatively we put an upper bound on $g_{t}^{A}\left(L_{t}, 0\right)=\bar{g}^{A}$ for all $L_{t}>\bar{L}$ then there is a threshold value for $\bar{g}^{A}$ or for the population size $\bar{L}$ which will determine whether the economy will grow or stay underdeveloped.

\footnotetext{
${ }^{15}$ Note that for this condition to hold as $L_{t}$ goes to infinity, the marginal product of $L_{t}$ has to go to zero.
} 
The fact whether child labor or schooling are optimal changes only the slope of the curves at the regime switching point. If schooling becomes optimal the slope increases, a regime change to zero child labor flattens the slope at all income levels. Shocks to income per capita (and implicitly survival rate) or relative child productivity have thus the potential to lift the economy out of a development trap.

However, if mortality rates are sufficiently high, a ban of child labor (by setting $\theta=0$ ) is not a guarantee for a kickoff of the development process. As suggested in proposition 3 the value of $q_{t}$ beyond which parents invest into education decreases with $\theta$ but if $q_{t}<\tilde{q}_{t}$ then education will be nevertheless zero. ${ }^{16}$ Thinking in dynamic terms, eradicating child labor has a positive effect on average wages, survival rates and therefore the number of future newborns will drop which induces parents to send children to school earlier. Thus, abolishing child labor may not have immediate benefits for growth but will pay off only in the future.

\subsection{A calibration exercise}

This subsection contains a calibrated version of the model and discusses the dynamic development of the economy. Obviously, this highly stylized model will not be able to capture the complexity of the real world. Due to the simple structure we can only focus on a limited number of calibration targets. Therefore, the primary target of this section is to demonstrate that this type of model is able to track observed historical developments and provide some quantitative guidance. For an easier comparison with real data the model's predictions are transformed into annualized growth rates according to $g_{r}^{x}=\left(1+g_{m}^{x}\right)^{1 / J}-1$ where $g_{r, m}^{x}$ are the growth rates for real $(r)$ and model time $(m)$ for variable $x$ and $J$ is a proxy for the length of a period and chosen to be 20. Although this choice is common in the literature (Lagerlöf (2006), Boldrin and Jones (2002)) one has to keep in mind that this has a a large effect on the growth rates when transformed from the generational time dimension to yearly growth rates.

In order to simulate the entire system we need to fix parametric forms for the equations determining the evolution of the survival rate and technological progress. We choose

$$
\begin{aligned}
q_{t+1} & =1-\frac{\varphi_{1}}{y_{t}^{\varphi_{2}}} \\
g_{t}^{A} & =\omega_{1} L_{t}^{\lambda_{1}}+\omega_{2} s_{t}^{\lambda_{2}} .
\end{aligned}
$$

These functional forms satisfy the conditions outlined above and the parameters were calibrated to provide realistic time paths for the endogenous variables. The exact functional form is not important for the qualitative behavior of the system.

The calibration targets on the household level were the number of children (fertility) and income share generated by working children. Total fertility rate in the $19^{\text {th }}$ century fluctuated around 5 in European countries (Galor (2005)) and according to Patrinos and Psacharopoulos (1997) working children in Peru contributed around 14\% to family income. Historical numbers are less reliable but are in the same order of magnitude. Assuming that woman's wages are around $50 \%$ of men (Galor (2005), page 233), children contribute in our model about $14 \%$ to family income at the beginning of the development process. The human capital production

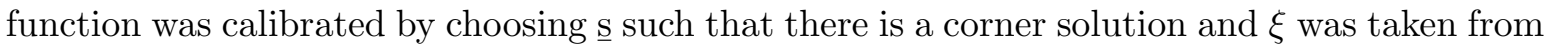

\footnotetext{
${ }^{16}$ See Patrinos and Psacharopoulos (1997) on this issue who also argue that due to income effects, not working does not automatically imply that children are attending school.
} 
Browning et al. (1999). The weights in the utility function were calibrated such that there is a regime with child labor but no schooling, an intermediate regime with working and learning children and finally a situation without child labor. Further, we choose the parameters of the household model such that population is stationary in steady state.

On the macroeconomic level we want to generate the typical inverted U-shape for population growth, initially low growth of wages but accelerating growth rate of TFP (and equivalently of wages) as soon as schooling becomes optimal and asymptotic convergence of child mortality to zero. For growth of wages we use the numbers from Hansen and Prescott (2002) as a calibration target. The share of human capital in the production function is also taken from the same source. The remaining parameters of equation (25) and (24) have no empirical counterparts ${ }^{17}$ but were calibrated such that the model is able to generate an economic and demographic transition within a sensible time period of about 20 generations. As can be seen in the graphs below, the largest part of the decrease in mortality risk and the demographic transition is achieved within this time window. Also the adjustment of schooling, wage growth and number of children from initial to near steady state levels is completed within a reasonable period. All parameters and initial conditions are summarized in table 1.

Table 1: Summary of Parameters and Initial Conditions

\begin{tabular}{lcccc}
\hline Household & $v$ & 0.33 & $\gamma_{1}$ & 0.30 \\
& $\underline{\mathrm{s}}$ & 0.20 & $\gamma_{2}$ & 0.60 \\
& $\xi$ & 0.80 & $\gamma_{3}$ & 0.10 \\
& $\theta$ & 0.09 & & \\
& & & & \\
\hline Survival Rate & $\varphi_{1}$ & 0.24 & & \\
& $\varphi_{2}$ & 0.90 & & \\
& & & & \\
\hline TFP Growth & $\omega_{1}$ & 0.06 & $\omega_{2}$ & 1.80 \\
& $\lambda_{1}$ & 0.20 & $\lambda_{2}$ & 1.50 \\
& & & & \\
\hline Production Function & $\alpha$ & 0.60 & & \\
& & & & \\
\hline Initial Conditions & $A_{0}$ & 1 & $T$ & 40 \\
& $L_{0}$ & 10 & $q_{0}\left(y_{0}\right)$ & 0.5
\end{tabular}

As a first step, in figure 7 we look at the household solutions generated by the baseline calibration from table 1 . The number of children is high but decreasing due to falling mortality. ${ }^{18}$ Due to rising survival rates, parents decrease their precautionary demand for children. At this stage of development this is the only reason why fertility is falling. Obviously, this is not the main source of the demographic transition. ${ }^{19}$ Education is initially not zero and child labor supply is positive. Later, the survival rate approaches the critical threshold above

\footnotetext{
${ }^{17}$ We only know from several studies (Cutler et al. (2006), Kalemli-Ozcan (2003)) that there is a concave relationship between income and survival probabilities which dictates $\varphi_{2}<1$.

${ }^{18} \mathrm{In}$ this graph the number of children is shown as per family which is twice the number from the model solution where each individual is allowed to have children.

${ }^{19}$ This result is also confirmed by Doepke (2005) who finds that a reduction in survival risk reduces total fertility but eventually concludes that the dramatic fall in the net reproduction rate (number of surviving daughters) must have been caused by other factors than declining child or infant morality.
} 
which optimal education becomes investment becomes positive. From this point in time onwards parents face also an additional quantity-quality trade off. The falling precautionary demand is now augmented by the quantity-quality trade off. Thus, the optimal number of offsprings starts to drop dramatically. Simultaneously, child labor is decreasing and later endogenously abandoned. The entire adjustment process from high fertility, high child labor and no schooling environment to a situation without child labor, low fertility and schooling investment is completed in less than 15 generations. The panel in the south-east of the graph shows the share of income spent on consumption. During the development process, parents not only decrease fertility but increase spending on the quality of children but are also able to increase own consumption.
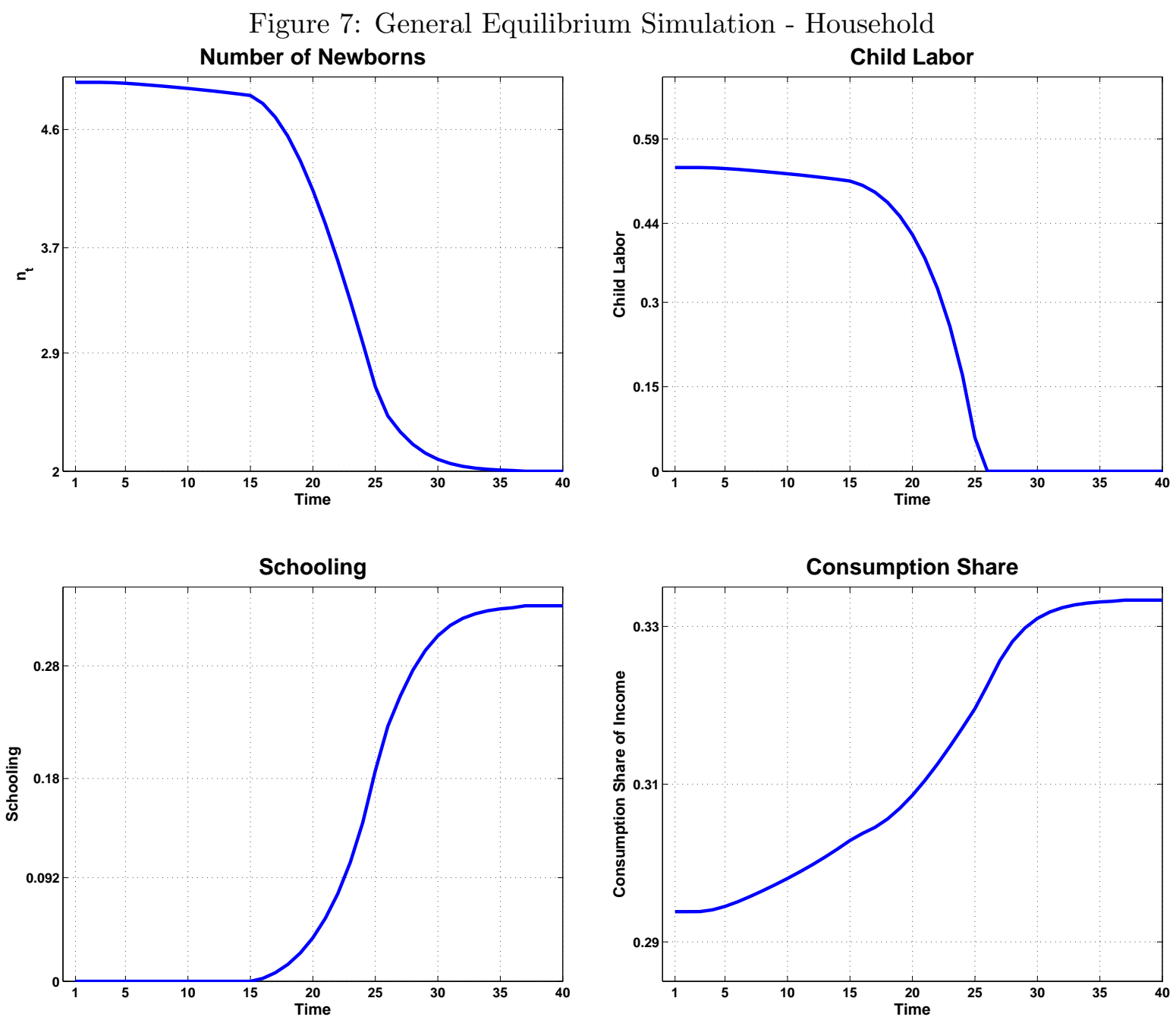

Figure 8 shows the time paths of several macroeconomic variables. Initially, the population growth rate is around $1 \%$ but starts rising as mortality (panel to the right) falls, reaches the maximum level at $1.7 \%$ and drops then monotonically to the steady state value of no population growth (by construction). The reason for the accelerating population growth is the insufficient drop in the number of children. As can be seen in the household solution the number of children is falling as the survival rate increases. However, this drop is not enough to counterbalance falling mortality. Thus, the total effect is that population growth 
is rising. The demographic transition starts to unfold only as parents start to invest into schooling. This can also be seen from the panel displaying the evolution of wage and TFP growth. Initially, the growth rate of TFP is just enough to counterbalance the growth of population and hence income per capita is growing only slowly. ${ }^{20}$ This is also reflected in only small increases of the survival rate. However, as the survival rate passes the critical threshold value agents start to educate children which boosts growth of TFP and wages. This feeds back into falling mortality and falling population growth. Eventually, child mortality is almost eliminated and the model converges to its steady state solution with a constant household decisions and constant growth rates. In this calibration, the contribution of the scale effect $\left(L_{t}\right)$ and of schooling to technological progress is approximately the same.

Figure 8: General Equilibrium Simulation - Macro
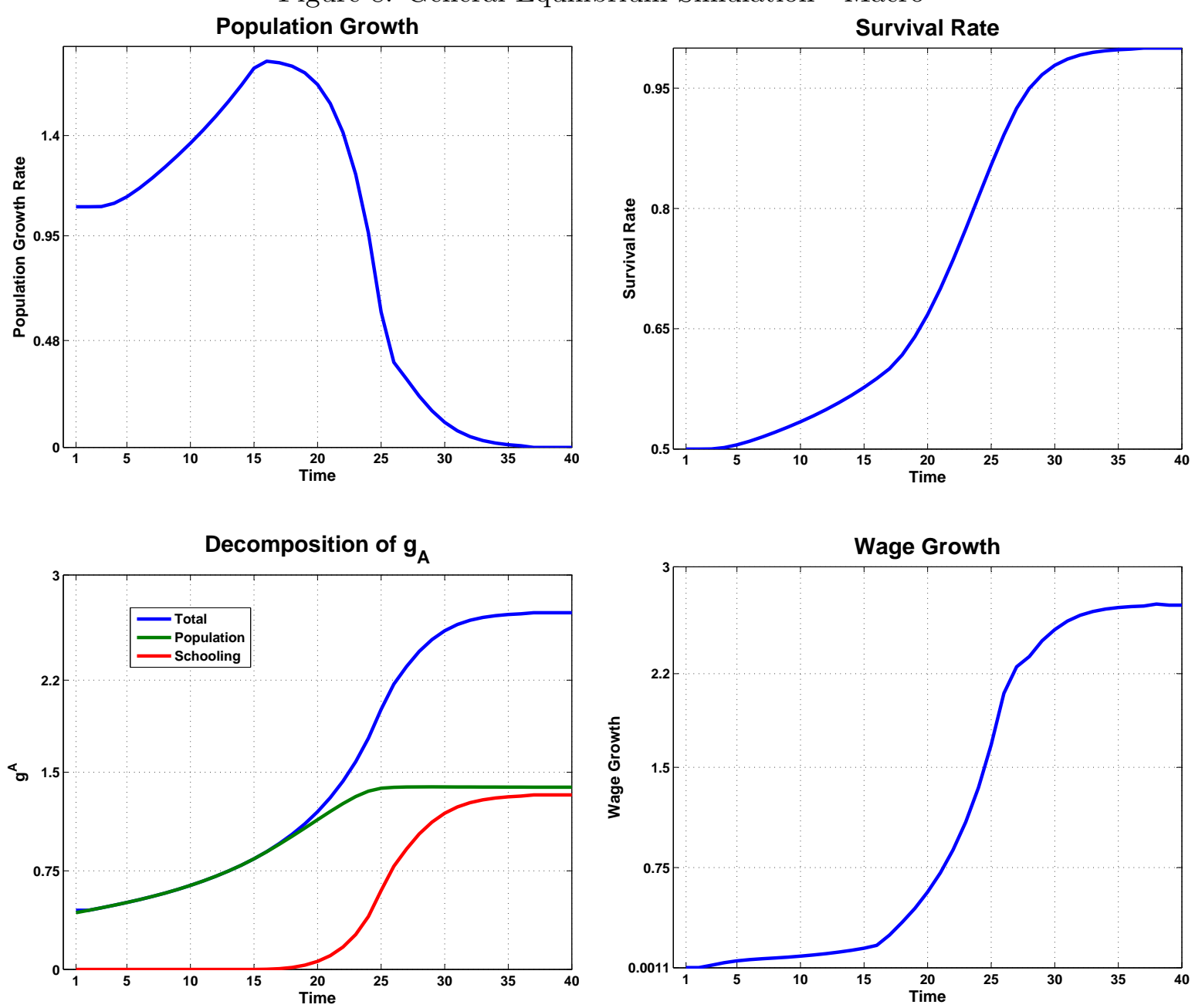

It can be already seen in graph 7 that the number of newborns decreases only slightly if schooling is zero. The falling fertility is only due to falling survival risk. However, it is rather obvious that this effect is not enough to bring fertility down to levels low enough generating a genuine demographic transition. Observe that in figure 8 for low values of $q$ the population is growing even with falling fertility. This result is not driven by the choice of parameters but it

\footnotetext{
${ }^{20}$ Initially TFP growth is only fueled by rising population since educational investment is zero.
} 
is rather a general feature of the model. Figure 9 shows the elasticity of the number of birth with respect to the survival rate for different parameter constellations. ${ }^{21}$ We generate three different scenarios ranging from a situation where child labor and schooling do no not overlap (labeled "no interior solution") to the situation in which children attend school and work at the same time (labeled "interior solution") and a parameter constellation without child labor but positive schooling over the entire range of $q$ (labeled "no child labor"). To generate this solutions we have to adjust some parameters of the model but leave the initial conditions unchanged. We set $\theta=0$ in order to obtain the solution without child labor. The graph without an interior solution is created by setting $\underline{\mathrm{s}}=0.24$ and $\gamma_{3}=0.4$ which corresponds to a situation in which child labor is abandoned early, followed by a situation without child labor (but still no schooling) and positive schooling investment only later.

It can be seen that without schooling, the elasticity is rather small (and always well below unity) without the potential to generate a demographic transition. The necessary condition is the introduction of a quantity-quality trade off via the investment into schooling. This result is rather insensitive to the parameter choice.

Figure 9: Elasticity of Children w.r.t. Mortality
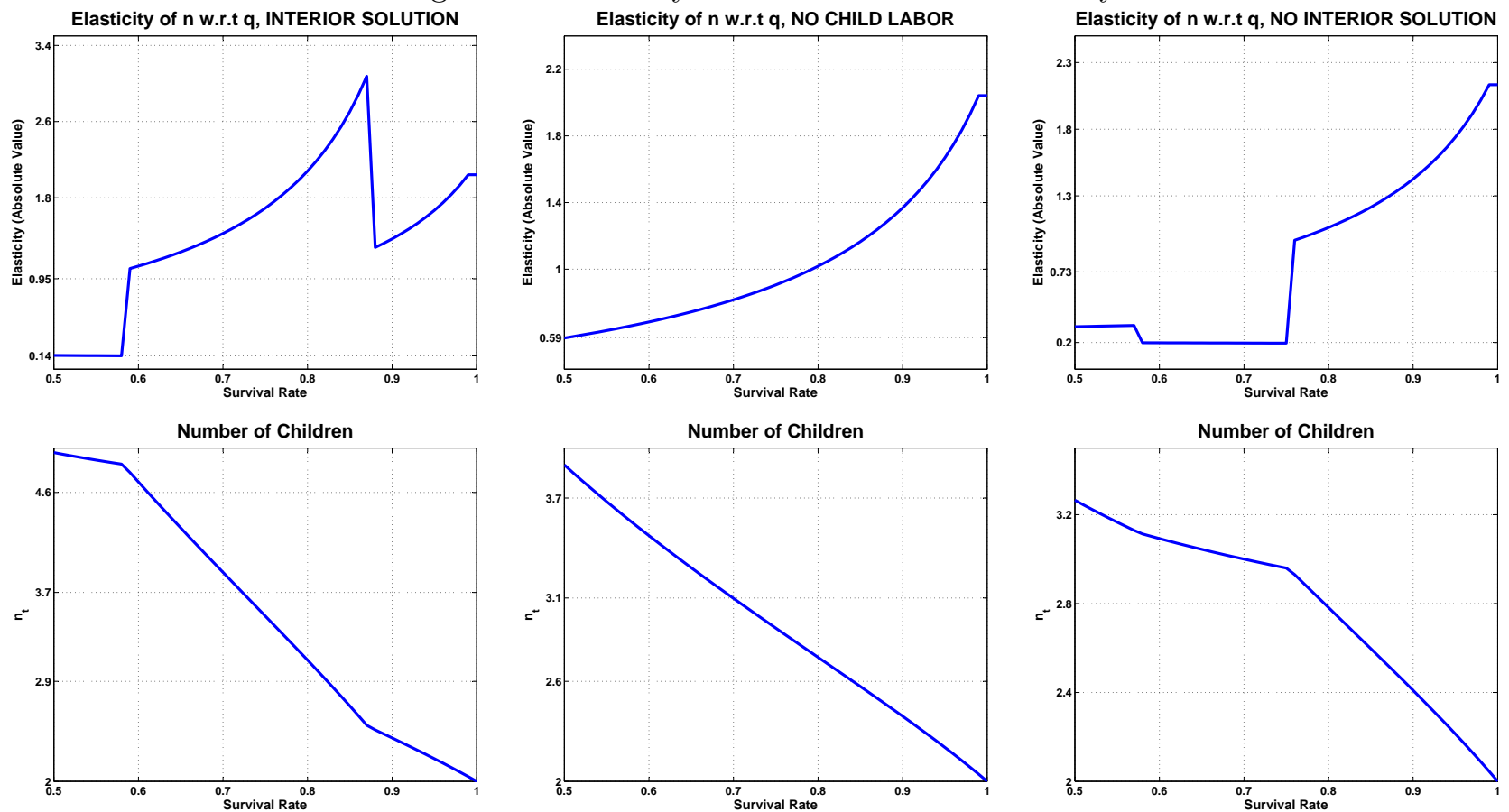

\section{Conclusion}

This paper analyzes the dynamic co-movement of fertility, schooling and child labor assuming that child survival is uncertain. In early stages of development the economy is characterized by low income, high mortality, high fertility and child labor. Due to rising technological progress, however, income starts to grow and so will the survival probability of children.

\footnotetext{
${ }^{21}$ Note that these graphs have the survival rate $q$ on the horizontal axis.
} 
Therefore parents will start to decrease their precautionary demand for children. Because the pure effect of falling mortality is not sufficient to generate a large quantitative change in the number of children, the population growth rate is still accelerating and thus the growth rate of resources per capita is rather low. At some point, however, parents will start to invest into schooling accelerating the development process. This change will induce a sizable drop in fertility which is the trigger of a demographic transition. Eventually population growth starts to decline and the economy converges to a balanced growth equilibrium. Along the development process child labor will be abandoned as parents decide to shift more resources to child quality and the need for many offsprings (due to high mortality) vanishes.

We show that child labor has an adverse effect on development in a sense that even if parents value child leisure, child labor will delay investment into schooling. If the survival chances of children are sufficiently low a ban of child labor, however, does not necessarily induce parents to invest into schooling. On the other hand, the model's prediction is that the effect of falling mortality alone is not sufficient to induce a large behavioral change. Thus, the demographic transition can only be explained by the rise of education and thus a quantity-quality trade off.

On the macroeconomic side we analyze the conditions for stagnation and endogenous growth. Without a link between population size and technological progress (or an upper bound on technological progress) the economy can be stuck in a Malthusian equilibrium with low income, high fertility, child labor and no human capital investment or transit into an endogenous growth regime which characterizes modern economies. The outcome depends on the parameters of the model and therefore multiple equilibria are possible. If technological progress depends on the size of the population the economy is likely to escape from the domain of attraction of the Malthusian "trap" except a knife-edge condition is satisfied. 


\section{A Proofs}

Proof of proposition 1 ( $n_{t}$ is decreasing in $q_{t}$ ). Rewriting the first order conditions from the text and rearranging them gives

$$
\begin{array}{lll}
F\left(n_{t}, q_{t}\right)=n_{t}\left[\frac{n_{t}(v-\underline{\mathrm{s}}-\theta) \gamma_{1}+\xi \gamma_{2}+\gamma_{3}}{1-n_{t}(v-\underline{\mathrm{s}}-\theta)}-\gamma_{2}\right]-\gamma_{2} \frac{1-q_{t}}{2 q_{t}} & \ell_{t}>0, s_{t}>0 \\
F\left(n_{t}, q_{t}\right)=n_{t}\left[\frac{n_{t}(v-\theta) \gamma_{1}+\gamma_{3}}{1-n_{t}(v-\theta)}-\gamma_{2}\right]-\gamma_{2} \frac{1-q_{t}}{2 q_{t}} & \ell_{t}>0, s_{t}=0 \\
F\left(n_{t}, q_{t}\right)=n_{t}\left[\frac{n_{t}(v-\underline{\mathrm{s}}) \gamma_{1}+\xi \gamma_{2}}{1-n_{t}(v-\underline{\mathrm{s}})}-\gamma_{2}\right]-\gamma_{2} \frac{1-q_{t}}{2 q_{t}} & \ell_{t}=0, s_{t}>0 \\
F\left(n_{t}, q_{t}\right)=n_{t}\left[\frac{v \gamma_{1} n_{t}}{1-n_{t} v}-\gamma_{2}\right]-\gamma_{2} \frac{1-q_{t}}{2 q_{t}} & \ell_{t}=0, s_{t}=0
\end{array}
$$

Each of these equations implicitly defines $n_{t}=n_{t}\left(q_{t}\right)$. Note that the left part (the left hand side in the FOC) is only a function of $n_{t}$ and the the right part (the right hand side in the FOC) is only a function of $q_{t}$. Thus, the effect of changing survival probabilities on the optimal number of children is given by

$$
\frac{\partial n_{t}}{\partial q_{t}}=-\frac{\partial F(\cdot) / \partial q_{t}}{\partial F(\cdot) / \partial n_{t}}
$$

Further, the behavior of the RSH for limiting cases of $q_{t}$ is given by

$$
\begin{aligned}
& \lim _{q_{t} \rightarrow 1} R H S=0 \\
& \lim _{q_{t} \rightarrow 0} R H S=\infty
\end{aligned}
$$

The LHS deserves more discussion. First observe that it holds that

$$
\begin{aligned}
& \lim _{n_{t} \rightarrow 0} L H S=0 \\
& \lim _{n_{t} \rightarrow 1 / v} L H S \begin{cases}=\infty & \text { if } \ell_{t}=0, s_{t}=0 \\
<\infty & \text { else }\end{cases}
\end{aligned}
$$

This implies that for all cases $\lim _{n_{t} \rightarrow 1 / v} L H S<\infty$ (i.e. the birth limit is binding) there is a lower bound $\tilde{q}_{t}$ which satisfies $F\left(n_{t}, q_{t}\right)=0$. For all $q_{t}<\tilde{q}_{t}$ the solution is $n_{t}=1 / v$.

To determine the sign of $\partial n_{t} / \partial q_{t}$ we need to evaluate the derivatives of RHS and LHS. 
The RHS of all cases is identical. Taking the derivative with respect to $q_{t}$ gives

$$
\frac{\partial F\left(n_{t}, q_{t}\right)}{\partial q_{t}}=\gamma_{2} \frac{1}{2 q_{t}^{2}}>0 \quad \forall \quad q_{t} \in(0,1) .
$$

The derivative of the LHS depends on the scenarios and is given by the following equations

$$
\begin{array}{rlrl}
\frac{\partial F\left(n_{t}, q_{t}\right)}{\partial n_{t}} & =\frac{n_{t} \tilde{v} \gamma_{1}\left(2-n_{t} \tilde{v}\right)+\xi \gamma_{2}+\gamma_{3}}{\left(1-n_{t} \tilde{v}\right)^{2}}-\gamma_{2} & & \ell_{t}>0, s_{t}>0 \\
\tilde{v} & \equiv v-\underline{\mathrm{s}}-\theta & & \ell_{t}>0, s_{t}=0 \\
\frac{\partial F\left(n_{t}, q_{t}\right)}{\partial n_{t}} & =\frac{n_{t} \tilde{v} \gamma_{1}\left(2-n_{t} \tilde{v}\right)+\gamma_{3}}{\left(1-n_{t} \tilde{v}\right)^{2}}-\gamma_{2} & & \\
\tilde{v} & \equiv v-\theta & & \ell_{t}=0, s_{t}>0 \\
\frac{\partial F\left(n_{t}, q_{t}\right)}{\partial n_{t}} & =\frac{n_{t} \tilde{v} \gamma_{1}\left(2-n_{t} \tilde{v}\right)+\xi \gamma_{2}}{\left(1-n_{t} \tilde{v}\right)^{2}}-\gamma_{2} & & \ell_{t}=0, s_{t}=0 \\
\tilde{v} & \equiv v-\underline{\mathrm{s}} &
\end{array}
$$

We have now to evaluate each of the cases in the range of all possible solutions for $n_{t}$. For the case of interior solutions we have

$$
\begin{aligned}
& \left.\frac{\partial F\left(n_{t}, q_{t}\right)}{\partial n_{t}}\right|_{n_{t}=0}=\gamma_{3}-\gamma_{2}(1-\xi) \\
& \left.\frac{\partial F\left(n_{t}, q_{t}\right)}{\partial n_{t}}\right|_{n_{t}=\frac{1}{v}}=\frac{\left(1-\left(\frac{\alpha+\theta}{v}\right)^{2}\right) \gamma_{1}+\gamma_{3}}{\left(\frac{\alpha+\theta}{v}\right)^{2}}+\gamma_{2}\left(\frac{\xi}{\left(\frac{\alpha+\theta}{v}\right)^{2}}-1\right)
\end{aligned}
$$

For the case without schooling but child labor

$$
\begin{aligned}
& \left.\frac{\partial F\left(n_{t}, q_{t}\right)}{\partial n_{t}}\right|_{n_{t}=0}=\gamma_{3}-\gamma_{2} \\
& \left.\frac{\partial F\left(n_{t}, q_{t}\right)}{\partial n_{t}}\right|_{n_{t}=\frac{1}{v}}=\frac{\left(1-\left(\frac{\theta}{v}\right)^{2}\right) \gamma_{1}+\gamma_{3}}{\left(\frac{\theta}{v}\right)^{2}}-\gamma_{2}
\end{aligned}
$$


For the case without child labor but schooling

$$
\begin{aligned}
& \left.\frac{\partial F\left(n_{t}, q_{t}\right)}{\partial n_{t}}\right|_{n_{t}=0}=\gamma_{2}(\xi-1) \\
& \left.\frac{\partial F\left(n_{t}, q_{t}\right)}{\partial n_{t}}\right|_{n_{t}=\frac{1}{v}}=\frac{\left(1-\left(\frac{\alpha}{v}\right)^{2}\right) \gamma_{1}}{\left(\frac{\alpha}{v}\right)^{2}}+\gamma_{2}\left(\frac{\xi}{\left(\frac{\alpha}{v}\right)^{2}}-1\right)
\end{aligned}
$$

However, if the model's parameters are such that there is a steady state with $q_{t}=1$ and schooling but no child labor, then the parameter restriction $\xi>\frac{\alpha}{v}$ has to hold. Using this it is clear that the second parenthesis is positive. And for the case with zero schooling but also no child labor

$$
\begin{aligned}
& \left.\frac{\partial F\left(n_{t}, q_{t}\right)}{\partial n_{t}}\right|_{n_{t}=0}=-\gamma_{2} \\
& \left.\frac{\partial F\left(n_{t}, q_{t}\right)}{\partial n_{t}}\right|_{n_{t}=\frac{1}{v}}=\infty
\end{aligned}
$$

Further, it can be shown under the parameter restrictions (essentially assumptions 1 and 3) the following holds

$$
\begin{aligned}
\left.\frac{\partial F\left(n_{t}, q_{t}\right)}{\partial n_{t}}\right|_{n_{t}=\frac{1}{v}} & >\left.\frac{\partial F\left(n_{t}, q_{t}\right)}{\partial n_{t}}\right|_{n_{t}=0} \\
\frac{\partial^{2} F\left(n_{t}, q_{t}\right)}{\partial n_{t}^{2}} & =\frac{2(v-\underline{\mathrm{s}}-\theta)\left(\gamma_{1}+\xi \gamma_{2}+\gamma_{3}\right)}{(-1+n(v-\underline{\mathrm{s}}-\theta))^{3}}<0
\end{aligned}
$$

This ensures monotonicity of the derivatives. If assumptions 1 or 3 are violated then $\partial F / \partial n$ may turn positive leading to two possible positive solutions.

Proof of proposition $2\left(\partial s_{t} / \partial q_{t}>0\right.$ and $\left.\partial \ell_{t} / \partial q<0\right)$. Use equations (8a) and (9a), take the derivative with respect to $q_{t}$ and use the result $\partial n_{t} / \partial q_{t}<0$ from proposition 1 . Then the claim

$$
\frac{\partial s_{t}}{\partial q_{t}}=\frac{\xi \gamma_{2}}{\gamma_{1}+\xi \gamma_{2}+\gamma_{3}} \frac{-\partial n_{t} / \partial q_{t}}{n_{t}^{2}}>0
$$

is established where for the solution without child labor the parameter $\gamma_{3}$ is set to zero. To prove that child labor is decreasing if the survival probability increases use equations (8b) and 
(7a) and take the derivative with respect to $q_{t}$. The result is

$$
\frac{\partial \ell_{t}}{\partial q_{t}}=-\frac{\gamma_{3}}{\gamma_{1}+\gamma_{3}+\xi \gamma_{2}} \frac{-\partial n_{t} / \partial q_{t}}{n_{t}^{2}}<0
$$

where we again use the result $\partial n_{t} / \partial q_{t}<0$ from proposition 1 . In case of a solution without schooling we have to set $\xi \gamma_{2}=0$ which does not change the sign.

Proof of proposition 4 (population growth is a hump-shaped function). Rewriting equations (8c), (7b), (9b) and (10) as

$$
F\left(n_{t}, q_{t}\right) \equiv n_{t}\left(\frac{n_{t} \tilde{v} \gamma_{1}+\xi \gamma_{2}+\gamma_{3}}{1-n_{t} \tilde{v}}-\gamma_{2}\right)-\gamma_{2} \frac{1-q_{t}}{2 q_{t}}=0
$$

where $\tilde{v}, \xi \gamma_{2}$ and $\gamma_{3}$ depend on the optimal regime (see equations in the text). Denoting the population growth factor as $L_{t+1} / L_{t} \equiv g_{N}$ and using $L_{t+1} / L_{t}=n_{t} q_{t}$ gives $n_{t}=g_{N} / q$. Inserting this into the above equation and rearranging gives

$$
F\left(g_{N}, q_{t}\right) \equiv 2 g_{N}^{2} \tilde{v} \gamma_{1}+\left(g_{N} \tilde{v}-q\right)\left(1+2 g_{N}-q\right) \gamma_{2}+2 g_{N} q\left(\gamma_{3}+\xi \gamma_{2}\right)
$$

The change in population growth as a function of the survival rate is then

$$
\frac{\partial g_{N}}{\partial q}=-\frac{\partial F / \partial q}{\partial F / \partial g_{N}}=\frac{-\gamma_{2}+\left(2 q-g_{N}(\tilde{v}+2)\right) \gamma_{2}+g_{N} 2\left(\gamma_{3}+\xi \gamma_{2}\right)}{-\gamma_{2} \tilde{v}\left(1+2 g_{N}-q\right)+2\left(\gamma_{2} q-2 g_{N} \tilde{v} \gamma_{1}\right)-2 q\left(\gamma_{3}+\xi \gamma_{2}\right)}
$$

At $q=0$ and $g_{N}=0$ this gives $1 / \tilde{v}$ which is always positive. ${ }^{22}$ However, if $q=1$ we have $g_{N}=\frac{(1-\xi) \gamma_{2}}{(v-\underline{\mathbf{S}})\left(\gamma_{1}+\gamma_{2}\right)}$ from the steady state solution with positive schooling and no child labor. Using this gives

$$
\frac{\partial g_{N}}{\partial q}=\frac{\left(g_{N}(2+\tilde{v})-1\right) \gamma_{2}-2 g_{N} \xi \gamma_{2}}{4 g_{N} \tilde{v} \gamma_{1}-2\left(1-2 \tilde{v} g_{N}\right) \gamma_{2}+2 \xi \gamma_{2}}
$$

Assuming that schooling has high returns, i.e. $\xi$ is approaching unity, the derivative is unambiguously negative. However, for all $\xi$ the condition ensuring declining population growth at high survival rates is

$$
\frac{(1-\xi) \gamma_{2}}{\tilde{v}\left(\gamma_{1}+\gamma_{2}\right)}(2(1-\xi)+\tilde{v})<1
$$

\footnotetext{
${ }^{22}$ This does not imply that the population growth rate is positive. It only means that it is increasing.
} 
where we have used $g_{N}$ as specified as above.

The proof for the non-monotonic behavior of the shape (i.e. second derivative) involves two steps. First, observe that the population growth rate is a strictly concave function of the survival rate (and therefore for all regimes). Assume now that we have parameter values and a $q_{t}$ such that we have an interior solution with positive schooling and child labor. Thus, if $\partial g_{N} / \partial q<0$ evaluated at $\tilde{n}_{t}{ }^{23}$ holds, then then $g_{N}$ at this point must be below the local maximum. Further note that we can rewrite

$$
\frac{\partial g_{N}}{\partial q_{t}}=\frac{\partial n_{t}}{\partial q_{t}} q_{t}+n_{t}
$$

which implies that

$$
\left.\frac{\partial g_{N}}{\partial q_{t}}\right|_{\ell, s>0}<\left.\frac{\partial g_{N}}{\partial q_{t}}\right|_{\ell=0, s>0} .
$$

Second, it follows that if $\partial g_{N} / \partial q<0$ evaluated at $\tilde{n}_{t}$ is negative for the solution without child labor but positive schooling (i.e. after the regime switch), then this derivative must be smaller (i.e. more negative). Due to strict concavity, $g_{N}$ drops monotonically to the steady state value. If the derivative is positive, then there will be a second local maximum because the population growth rate will rise to a second local maximum.

On the other hand, if $\partial g_{N} / \partial q>0$ holds for the interior solution then the population growth rate will continue to rise after the endogenous regime switch (see derivative above) and eventually start to decline after a local maximum converging monotonically to the steady state value.

Proof of proposition $5\left(\partial n_{t} / \partial \theta>0\right)$. Use equations (8c) and (7b), redefine $\tilde{v} \equiv v-\alpha$ and $\varphi \equiv \xi \gamma_{2}+\gamma_{3}$ if schooling and labor are interior and $\tilde{v} \equiv v$ and $\varphi \equiv \gamma_{3}$ if only child labor is optimal. Then, the first order condition for children can be written as

$$
F\left(n_{t}, \theta\right)=n_{t}\left[\frac{n_{t}(\tilde{v}-\theta) \gamma_{1}+\varphi}{1-n_{t}(\tilde{v}-\theta)}-\gamma_{2}\right]-\gamma_{2} 2 \frac{1-q_{t}}{q_{t}}
$$

\footnotetext{
${ }^{23}$ Recall that $\tilde{n}_{t}$ is the point where the household endogenously switches from the interior regime to the regime without child labor but schooling.
} 
The result can be established by showing that

$$
\frac{\partial n_{t}}{\partial \theta}=-\frac{\partial F / \partial \theta}{\partial F / \partial n_{t}}>0
$$

Proof of proposition 6 ( $\partial \ell_{t} / \partial \theta>0$ and $\left.\partial s_{t} / \partial \theta \gtrless 0\right)$. Use equations ( $\left.8 \mathrm{~b}\right)$ and $(7 \mathrm{a})$, redefine $\tilde{v} \equiv v-\underline{\mathrm{s}}$ and $\varphi \equiv \xi \gamma_{2}$ if schooling and labor supply are interior. Otherwise $\tilde{v} \equiv v$ and $\varphi \equiv 0$. Taking then the derivative with respect to $\theta$ is

$$
\frac{\partial \ell_{t}}{\partial \theta}=-\frac{\gamma_{3}}{\gamma_{1}+\varphi+\gamma_{3}}\left(\frac{-\frac{\partial n_{t}}{\partial \theta} \theta-\left(1-n_{t} \tilde{v}\right) n_{t}}{\left(n_{t} \theta\right)^{2}}\right)>0
$$

where we use the fact that $\partial n_{t} / \partial \theta>0$ from proposition 5 . To show the relationship between schooling and relative productivity use equation (8a) and take the derivative with respect to $\theta$. The result is

$$
\frac{\partial s_{t}}{\partial \theta}=\frac{\xi \gamma_{2}}{\gamma_{1}+\xi \gamma_{2}+\gamma_{3}}\left(1-\frac{\partial n_{t} / \partial \theta}{n_{t}^{2}}\right) \gtrless 0
$$

where $\partial n_{t} / \partial \theta>0$ from proposition 5 . The result that $\frac{\partial s t}{\partial \theta}<0$ cannot be established analytically since it depends on the equilibrium value of $n_{t}$. However, in the numerical simulations it turns out that the equilibrium solution is always such that the claim above always holds.

Proof that $n_{t}$ has always a positive and a negative root if there is an. unrestricted

(i.e. interior) solution. Using equation (5c) and replacing $\lambda$ with $\gamma_{1} / c_{t}$ gives

$$
\frac{\gamma_{1}}{c_{t}} w_{t} h_{t}\left(v+s_{t}-\theta \ell_{t}\right)=\gamma_{2}\left[\frac{1}{n_{t}}+\frac{\left(1-q_{t}\right)}{2 n_{t}^{2} q_{t}}\right]
$$

Rearrange this equation to obtain

$$
-\frac{\gamma_{1}}{\gamma_{2}} \frac{w_{t} h_{t}\left(v+s_{t}-\theta \ell_{t}\right)}{c_{t}} n_{t}^{2}+n_{t}+\frac{1-q_{t}}{2 q_{t}}=0
$$

Solving this quadratic equation for $n_{t}$ proves the claim. 


\section{B Approximation of Expected Utility}

Approximation of Expected Utility Maximization. The $3^{\text {rd }}$ order Taylor series approximation of the utility function $U\left(n_{t} q_{t}\right)=\log n_{t} q_{t}$ around the mean $\bar{n}_{t}$ is

$$
U\left(n_{t} q_{t}\right)=\log \bar{n}_{t}+\left(\bar{n}_{t}-n_{t} q_{t}\right) \frac{1}{\bar{n}_{t}}-\frac{\left(\bar{n}_{t}-n_{t} q_{t}\right)^{2}}{2 !} \frac{1}{\bar{n}_{t}^{2}}+\frac{\left(\bar{n}_{t}-n_{t} q_{t}\right)}{3 !} \frac{2}{\bar{n}_{t}^{3}}
$$

Taking expectations gives then the result in the paper. The first term is evaluated at the mean, the second term vanishes due to $E\left[\bar{n}_{t}-n_{t} q_{t}\right]=0$, the third term is just $E\left[\left(\bar{n}_{t}-n_{t} q_{t}\right)^{2}\right]=$ $\operatorname{Var}\left(n_{t} q_{t}\right)=n_{t} q_{t}\left(1-q_{t}\right)$ and the last term is also zero because of the symmetry of the binomial distribution. Since we use a utility function which is unbounded from below and a distribution with mass on zero, we would have to include an arbitrary small constant into the utility function. However, this would not affect any of the results. 


\section{References}

Baland, J.-M. and J. A. Robinson (2000). Is child labor inefficient? Journal of Political Economy 108(4), 663-679.

Basu, K. and P. H. Van (1998). The economics of child labor. American Economic Review $88(3), 412-427$.

Becker, G. S. (1960). An economic analysis of fertility. In G. S. Becker (Ed.), Demographic and Economic Change in Developed Countries, Princeton. Princeton University Press.

Becker, G. S. and G. H. Lewis (1973). On the interaction between the quantity and quality of children. Journal of Political Economy 81(2), S279-S288.

Boldrin, M. and L. E. Jones (2002). Mortality, fertility, and saving in a malthusian economy. Review of Economic Dynamics (5), 775-814.

Browning, M., L. P. Hansen, and J. J. Heckman (1999). Micro Data and General Equilibrium Models (J. Taylor and M. Woodford ed.)., Chapter 8, pp. 543-633. Handbook of Macroeconomics. Amsterdam: Elsevier.

Cervellati, M. and U. Sunde (2005). Human capital formation, life expectancy, and the process of development. American Economic Review 95(5), 1653-1672.

Crafts, N. and T. C. Mills (2007). From malthus to solow: How did the malthusian economy really evolve? Journal of Macroeconomics. forthcoming.

Cutler, D., A. Deaton, and A. Lleras-Muney (2006). The determinants of mortality. Journal of Economic Perspectives 20(3), 97-120.

de la Croix, D. and M. Doepke (2003). Inequality and growth: Why differential fertility matters. American Economic Review 93(4), 1091-1113.

Dessy, S. E. (2000). A defense of compulsive measures against child labor. Journal of Development Economics 62, 261-275.

Diamond, J. (1998). Guns, Germs and Steel: A Short History of Everbody for the Last 13000 Years. Random House.

Doepke, M. (2005). Child mortality and fertility decline: Does the barro-becker model fit the facts? Journal of Population Economics 18, 337-366.

Eckstein, Z., P. Mira, and K. I. Wolpin (1999). A quantitative analysis of swedish fertility dynamics. Review of Economic Dynamics 2, 137-165.

Flora, P., F. Kraus, and W. Pfenning (1983). State Economy and Society in Western Europe 1815-1975, Volume 1. Chicago: St. James Press.

Galor, O. (2005). From Stagnation to Growth: Unified Growth Theory (Philippe Aghion and Steven N. Durlauf ed.)., Chapter 4, pp. 171-285. Handbook of Economic Growth. Amsterdam: Elsevier.

Galor, O. and O. Moav (2002). Natural selection and the origin of economic growth. Quarterly Journal of Economics 117, 1133-1192. 
Galor, O. and D. Weil (1996). The gender gap, fertility, and growth. American Economic Review 83(6), 374-87.

Galor, O. and D. Weil (2000). Population, technology, and growth: From malthusian stagnation to the demographic transition. American Economic Review 90(4), 806-828.

Gould, E. D., O. Moav, and A. Simhon (2008). The mystery of monogamy. American Economic Review 98(1), 333-357.

Hansen, G. D. and E. C. Prescott (2002). Malthus to solow. American Economic Review 92(4), 1205-1217.

Hazan, M. and B. Berdugo (2002). Child labor, fertility, and economic growth. The Economic Journal 11(482), 810-828.

Jones, C. I. (1995). R \& D-Based Models of Economic Growth. Journal of Political Economy 103(4), 759-784.

Jones, C. I. (2001). Was an industrial revolution inevitable? economic growth over the very long run. Advances in Macroeconomics 1(2), 1-43.

Kalemli-Ozcan, S. (2002). Does mortality decline promote economic growth? Journal of Economic Growth 7(4), 411-439.

Kalemli-Ozcan, S. (2003). A stochastic model of mortality, fertility, and human capital investment. Journal of Development Economics 70, 103-118.

Kalemli-Ozcan, S., H. E. Ryder, and D. N. Weil (2000). Mortality decline, human capital investment, and economic growth. Journal of Development Economics 62, 1-23.

Kögel, T. and A. Prskawetz (2001). Agricultural productivity growth and escape from the malthusian trap. Journal of Economic Growth 6, 337-357.

Kremer, M. (1993). Population growth and technological change: One million b.c. to 1990. Quarterly Journal of Economics 108(3), 681-716.

Lagerlöf, N.-P. (2006). The galor-weil model revisited: A quantitative exercise. Review of Economic Dynamics (9), 116-142.

Lebergott, S. (1964). Manpower in Economic Growth: The American Record Since 1800. New York: McGraw-Hill Book Company.

Maddison, A. (2001). The World Economy: Historical Statistics. OECD.

Patrinos, H. A. and G. Psacharopoulos (1997). Family size, schooling and child labor in peru - an empirical analysis. Journal of Population Economics 10(4), 387-405.

Psacharopoulos, G. (1997). Child labor versus educational attainment some evidence from latin america. Journal of Popualtion Economics 10(4), 377-386.

Ram, R. and T. W. Schultz (1979). Life span, health, savings, and productivity. Economic Development and Cultural Change 27(3), 399-421.

Sah, R. K. (1991). The effects of child mortality changes on fertility choice and parental welfare. Journal of Political Economy 99(3), 582-606. 
Strulik, H. (2004a). Child mortality, child labour and economic development. Economic Journal 114(497), 547-568.

Strulik, H. (2004b). Economic growth and stagnation with endogenous health and fertility. Journal of Population Economics 17, 433-453.

Tamura, R. (2006). Human capital and economic development. Journal of Development Economics 79(1), 26-72.

The World Bank (2004). World Development Indicators 2004.

Wolpin, K. I. (1997). Determinants and consequences of the mortality and health of infants and children (Mark R. Rosenzweig and Oded Stark ed.)., Chapter 10, pp. 483-557. Handbook of Population and Family Economics. Amsterdam: Elsevier. 


\begin{tabular}{|c|c|c|}
\hline Nr. & Author & Title \\
\hline $08-48$ & $\begin{array}{l}\text { Daniel Schunk } \\
\text { Johannes Binswanger }\end{array}$ & $\begin{array}{l}\text { What is an Adequate Standard of Living during } \\
\text { Retirement? }\end{array}$ \\
\hline $08-47$ & $\begin{array}{l}\text { Alexander Ludwig } \\
\text { Michael Reiter }\end{array}$ & $\begin{array}{l}\text { Sharing Demographic Risk - Who is Afraid of the } \\
\text { Baby Bust? }\end{array}$ \\
\hline $08-46$ & $\begin{array}{l}\text { Martin von Gaudecker } \\
\text { Arthur van Soest } \\
\text { Erik Wengström }\end{array}$ & $\begin{array}{l}\text { Selection and Mode Effects in Risk Preference } \\
\text { Elicitation Experiments }\end{array}$ \\
\hline $08-45$ & $\begin{array}{l}\text { Axel Börsch-Supan } \\
\text { Tabea Bucher-Koenen } \\
\text { Anette Reil-Held } \\
\text { Christina Wilke }\end{array}$ & $\begin{array}{l}\text { Zum künftigen Stellenwert der ersten Säule im } \\
\text { Gesamtsystem der Alterssicherung }\end{array}$ \\
\hline $08-44$ & $\begin{array}{l}\text { Tabea Bucher-Koenen } \\
\text { Christina Wilke }\end{array}$ & $\begin{array}{l}\text { Zur Anhebung der Altersgrenzen: Eine Simulation } \\
\text { der langfristigen Auswirkungen auf die gesetzliche } \\
\text { Rentenversicherung bei unterschiedlichem } \\
\text { Renteneintrittsverhalten }\end{array}$ \\
\hline $08-43$ & $\begin{array}{l}\text { Alexander Ludwig } \\
\text { Thomas Schelkle } \\
\text { Edgar Vogel }\end{array}$ & $\begin{array}{l}\text { Demographic Change, Human Capital and } \\
\text { Endogenous Growth }\end{array}$ \\
\hline $08-42$ & Edgar Vogel & $\begin{array}{l}\text { From Malthus to Modern Growth: Child Labor, } \\
\text { Schooling and Human Capital }\end{array}$ \\
\hline $08-41$ & Michael Ziegelmeyer & $\begin{array}{l}\text { Documentation of the logical imputation using the } \\
\text { panel structure of the 2003-2008 German SAVE } \\
\text { Survey }\end{array}$ \\
\hline $08-40$ & $\begin{array}{l}\text { Florian Kutzner } \\
\text { Tobias Vogel } \\
\text { Peter Freytag } \\
\text { Klaus Fiedler }\end{array}$ & $\begin{array}{l}\text { Pseudocontingencies in stereotype formation: } \\
\text { extending illusory correlations }\end{array}$ \\
\hline 08-39 & $\begin{array}{l}\text { Wendelin Schnedler } \\
\text { Adam Dominiak }\end{array}$ & $\begin{array}{l}\text { Uncertainty Aversion and Preference for } \\
\text { Randomization }\end{array}$ \\
\hline $08-38$ & $\begin{array}{l}\text { Susanne Abele } \\
\text { Sandra I. Vaughan-Parsons } \\
\text { Garold Stasser }\end{array}$ & $\begin{array}{l}\text { Information Flow and Influence during Collective } \\
\text { Search, Discussion, and Choice }\end{array}$ \\
\hline
\end{tabular}




\begin{tabular}{lll}
\hline \hline Nr. & Author & Title \\
\hline
\end{tabular}

08-37 Peter Freytag

Tobias Vogel

Florian Kutzner

Klaus Fiedler

08-36 Klaus Fiedler

Peter Freytag

Thorsten Meiser

08-35 Alexander Unger

Dagmar Stahlberg

08-34 Dirk Simons

Nicole Zein

08-33 Michael Bremert

Axel Schulten

08-32 Jürgen Eichberger

Ani Guerdjikova

08-31 Jürgen Eichberger

Simon Grant

Jean-Philippe Lefort

08-30 Vladimir I. Danilov

Gleb A. Koshevoy

Christine Lang

08-29 Thomas Gschwend

08-28 Michael Herrmann

08-27 Karl-Martin Ehrhart

Marion Ott

Susanne Abele

08-26 Michel Regenwetter
The reproduction of base-rates promotes pseudocontingencies

Pseudocontingencies: An Integrative Account of an Intriguing Cognitive Illusion

The Influence of Self-Regulation on Decision

Making

Kosten aus einer asymmetrischen

Informationsverteilung zwischen Abschlussprüfer und Mandant

The Impact of Supervisory Board Characteristics on Firm Performance

Case-Based Expected Utility: Preferences over Actions and Data

Neo-additive capacities and updating

Equilibria with indivisible goods and package-utilities

Electoral System Change in Belgium 2003: Party Strategies and Voter Responses

Expectations about Coalitions and Strategic Voting under Proportional Representation

Auction Fever: Theory and Experimental Evidence

Perspectives on Preference Aggregation 


\begin{tabular}{lll}
\hline \hline Nr. & Author & Title \\
\hline
\end{tabular}

08-25 Daniel M. Bernstein

Michael E. Rudd

Edgar Erdfelder

Ryan Godfrey

Elizabeth F. Loftus

08-24 Markus Glaser

Florencio Lopez de Silanes

Zacharias Sautner

08-23 Markus Glaser

Martin Weber

08-22 Markus Glaser

Thomas Langer

Jens Reynders

Martin Weber

08-21 Patrick A. Müller

Rainer Greifeneder

Dagmar Stahlberg

Kees Van den Bos

Herbert Bless

08-20 Patrick A. Müller

Rainer Greifeneder

Dagmar Stahlberg

Kees Van den Bos

Herbert Bless

08-19 Jana Janßen

Patrick A. Müller

Rainer Greifeneder

08-18 Rainer Greifeneder

Benjamin Scheibehenne

08-17 Paul Grout

Wendelin Schnedler

08-16 Clemens Kroneberg

Isolde Heintze

Guido Mehlkop
The Revelation Effect for Autobiographical

Memory: A Mixture-Model Analysis

Looking Inside a Conglomerate: Efficiency of Internal Capital Allocation and Managerial Power Within a Firm

Financial Literacy und Anlegerverhalten

Scale Dependence of Overconfidence in Stock Market Volatility Forecasts

The Role of Procedural Fairness in Trust and Trustful Behavior

The Influence of Accessibility Experiences on the Willingness to Cooperate in Negotiations

A field study on the role of ease-of-retrieval in procedural justice judgments

When choosing is difficult: Complexity and choice-overload

Non-Profit Organizations in a Bureaucratic Environment

On shoplifting and tax fraud: An action-theoretic analysis of crime 


\begin{tabular}{lll}
\hline \hline Nr. & Author & Title
\end{tabular}

08-15 Hermann Jahnke

Dirk Simons

08-14 Peter Dürsch

Jörg Oechssler

Radovan Vadovic

08-13 Carsten Schmidt

Martin Strobel

Henning Oskar Volkland

08-12 Mathias Sommer

08-11 Hans Gersbach

Hans Haller

08-10 Michael F. Meffert

Thomas Gschwend

08-09 Jens Wüstemann

Jannis Bischof

08-08 Jürgen Eichberger

David Kelsey

08-07 Jürgen Eichberger

Ani Guerdjikova

08-06 Jörg Oechssler

Andreas Roider

Patrick W. Schmitz

08-05 Jörg Oechssler

Andreas Roider

Patrick W. Schmitz

08-04 Julian Rode
A rationale for the payback criterion

Sick Pay Provision in Experimental Labor Markets

Accuracy, Certainty and Surprise - A Prediction

Market on the Outcome of the 2002 FIFA World

Cup

Understanding the trends in income, consumption and wealth inequality and how important are life-cycle effects?

Club Theory and Household Formation

Strategic Voting in Multiparty Systems: A Group Experiment

Ausweis von Finanzinstrumenten in europäischen Bankbilanzen nach IFRS: Normative Erkenntnisse empirischer Befunde

Are the Treasures of Game Theory Ambiguous?

Multiple Priors as Similarity Weighted Frequencies

Cooling-Off in Negotiations - Does It Work?

Cognitive Abilities and Behavioral Biases

Truth and trust in communication - Experiments on the effect of a competitive context 


\begin{tabular}{|c|c|c|}
\hline Nr. & "Author & $\begin{array}{l}\text { Title } \\
\end{array}$ \\
\hline $08-03$ & Volker Stocké & $\begin{array}{l}\text { Educational Decisions as Rational Choice? An } \\
\text { Empirical Test of the Erikson-Jonsson Model for } \\
\text { Explaining Educational Attainment }\end{array}$ \\
\hline 08-02 & $\begin{array}{l}\text { Siegfried K. Berninghaus } \\
\text { Karl-Martin Ehrhart } \\
\text { Marion Ott }\end{array}$ & $\begin{array}{l}\text { Myopically Forward-Looking Agents in a Network } \\
\text { Formation Game: Theory and Experimental } \\
\text { Evidence }\end{array}$ \\
\hline 08-01 & $\begin{array}{l}\text { Sascha Huber } \\
\text { Thomas Gschwend } \\
\text { Michael F. Meffert } \\
\text { Franz Urban Pappi }\end{array}$ & $\begin{array}{l}\text { Erwartungsbildung über den Wahlausgang und ihr } \\
\text { Einfluss auf die Wahlentscheidung }\end{array}$ \\
\hline $07-76$ & $\begin{array}{l}\text { Michael Bremert } \\
\text { Dennis Voeller } \\
\text { Nicole Zein }\end{array}$ & $\begin{array}{l}\text { Interdependencies between Elements of } \\
\text { Governance and Auditing: Evidence from Germany }\end{array}$ \\
\hline $07-75$ & $\begin{array}{l}\text { Jannis Bischof } \\
\text { Jens Wüstemann }\end{array}$ & $\begin{array}{l}\text { How Does Fair Value Measurement under IAS } 39 \\
\text { Affect Disclosure Choices of European Banks? }\end{array}$ \\
\hline $07-74$ & $\begin{array}{l}\text { Markus Glaser } \\
\text { Philipp Schäfers } \\
\text { Martin Weber }\end{array}$ & $\begin{array}{l}\text { Managerial Optimism and Corporate Investment: Is } \\
\text { the CEO Alone Responsible for the Relation? }\end{array}$ \\
\hline $07-73$ & $\begin{array}{l}\text { Jannis Bischof } \\
\text { Michael Ebert }\end{array}$ & $\begin{array}{l}\text { IAS } 39 \text { and Biases in the Risk Perception of } \\
\text { Financial Instruments }\end{array}$ \\
\hline $07-72$ & $\begin{array}{l}\text { Susanne Abele } \\
\text { Garold Stasser }\end{array}$ & $\begin{array}{l}\text { Continuous and Step-level Pay-off Functions in } \\
\text { Public Good Games: A Conceptual Analysis }\end{array}$ \\
\hline 07-71 & $\begin{array}{l}\text { Julian Rode } \\
\text { Marc Le Menestrel }\end{array}$ & The role of power for distributive fairness \\
\hline $07-70$ & $\begin{array}{l}\text { Markus Glaser } \\
\text { Martin Weber }\end{array}$ & $\begin{array}{l}\text { Why inexperienced investors do not learn: They do } \\
\text { not know their past portfolio performance }\end{array}$ \\
\hline $07-69$ & $\begin{array}{l}\text { Jose Apesteguia } \\
\text { Steffen Huck } \\
\text { Jörg Oechssler } \\
\text { Simon Weidenholzer }\end{array}$ & $\begin{array}{l}\text { Imitation and the Evolution of Walrasian Behavior: } \\
\text { Theoretically Fragile but Behaviorally Robust }\end{array}$ \\
\hline
\end{tabular}

